

\title{
Las poblaciones indígenas prehispánicas del río Paraná Inferior y Medio
}

\author{
Mariano Bonomo ${ }^{1,2}$, Violeta Di Prado ${ }^{1,2}$, Carolina Silva ${ }^{2}$, Clara Scabuzzo ${ }^{1,3}$, María Agustina Ramos van Raap ${ }^{1,2}$, \\ Carola Castiñeira ${ }^{1,4}$, María de los Milagros Colobig ${ }^{1,3}$ y Gustavo Politis ${ }^{1,2,5}$
Consejo Nacional de Investigaciones Científicas y Técnicas, Argentina
${ }^{2}$ División Arqueología, Facultad de Ciencias Naturales y Museo, Universidad Nacional de La Plata, Argentina. mbonomo@fcnym.unlp.edu.ar; violetadiprado@hotmail.com; karitosilva@gmail.com; ramosvanraap.ma@gmail.com
${ }^{3}$ Centro de Investigación Científica y de Transferencia Tecnológica a la Producción, Argentina. clarascabuzzo@hotmail.com; milagroscolobig@gmail.com
${ }^{4}$ Museo Argentino de Ciencias Naturales "Bernardino Rivadavia” y Facultad de Ciencias Naturales y Museo, Universidad Nacional de La Plata, Argentina. carolac12004@yahoo.com Provincia de Buenos Aires, Argentina. gpolitis@fcnym.unlp.edu.ar \\ ${ }^{5}$ Investigaciones Arqueológicas y Paleontológicas del Cuaternario Pampeano, Facultad de Ciencias Sociales, Universidad Nacional del Centro de la
}

\begin{abstract}
RESUMEN. En este trabajo se sintetiza y discute el estado actual del conocimiento en la arqueología del río Paraná en Argentina, con especial énfasis en los estudios sistemáticos que nuestro equipo de investigación viene desarrollando desde hace más de 10 años en el Delta Superior, sudoeste de la provincia de Entre Ríos. Como resultado de las investigaciones se prospectó un amplio sector del área de estudio, se registraron más de 80 sitios arqueológicos, de los cuales se excavaron ocho. A través de la conformación de un grupo interdisciplinario, se aportó información relevante en temas tales como la cronología de las ocupaciones humanas, el uso de los recursos faunísticos y botánicos, las prácticas de producción y uso de la alfarería y la caracterización de las prácticas mortuorias. A partir de la información geoarqueológica y arqueobotánica se confirmó la génesis antrópica de las construcciones monticulares o cerritos y la presencia de horticultura de maíz, porotos y zapallo. También se evaluó la existencia de un bajo nivel de jerarquización social (ya mencionado en las primeras crónicas del siglo XVI) en las poblaciones asociadas con la entidad arqueológica Goya-Malabrigo, la que podría ser una derivación de la expansión meridional de los arawak. Finalmente, se abordó el estudio de la dispersión de los guaraníes y los modos de interacción con las poblaciones locales. En suma, los avances en las investigaciones de la última década muestran un panorama más complejo que integra la historia indígena local a procesos adaptativos generales ocurridos a lo largo de las Tierras Bajas sudamericanas.
\end{abstract}

Palabras clave: Montículos, Prácticas mortuorias, Tecnología cerámica, Subsistencia, Nordeste argentino

ABSTRACT. The prehispanic indigenous populations from the Lower and Middle Paraná river. This paper synthesizes and discusses the current state of knowledge regarding the archeology of the Paraná River in Argentina, with special emphasis on the systematic studies that our research team has been performing for more than 10 years in the Upper Delta, in the southwestern Entre Ríos Province. As a result of our investigations, a 
large sector of the study area was surveyed where more than 80 archaeological sites were recorded and eight of them were excavated. Thanks to the assembly of an interdisciplinary team, relevant information was obtained on topics such as the chronology of human occupations, use of faunal and botanical resources, production and use of pottery, and the characterization of mortuary practices. The integration of geoarchaeological and archaeobotanical information allowed confirming the anthropic genesis of the mound constructions or cerritos and the presence of horticulture of corn, beans and squash. The existence of a low-level social hierarchy (already mentioned in the earliest $16^{\text {th }}$ century chronicles) was also evaluated for the populations associated with the Goya-Malabrigo archaeological entity, which could be a derivation of the southern expansion of the Arawak. Finally, the study of the dispersion of the Guarani and the ways of interaction with local populations was addressed. In sum, the advances made in the last decade of research paint a more complex panorama that integrates the local indigenous history into the general adaptive processes that occurred along South American Lowlands.

Keywords: Mounds, Mortuary practices, Pottery technology, Subsistence, Argentinean Northeast

RESUMO. As populações indígenas prehispánicas do rio Paraná Inferior e Médio. Este trabalho sintetiza e discute o estado atual do conhecimento na arqueologia do rio Paraná na Argentina, com ênfase especial nos estudos sistemáticos que nossa equipe de pesquisa vem desenvolvendo há mais de 10 anos no Delta Superior, sudoeste da província de Entre Ríos. Como resultado de nossas pesquisas, um amplo setor da área de estudo foi prospectado, mais de 80 sítios arqueológicos foram registrados, dos quais oito foram escavados. Por meio da formação de um grupo interdisciplinar, foram fornecidas informações relevantes sobre tópicos como a cronologia das ocupações humanas, o uso de recursos faunísticos e botânicos, as práticas de produção e uso de cerâmica e a caracterização de práticas mortuárias. A partir das informações geoarqueológicas e arqueobotânicas, a gênese antrópica das construções monticulares ou cerritos e a presença de horticultura de milho, feijão e abóbora foram confirmadas. Também se avaliou a existência de um baixo nível de hierarquização social (já mencionado nas primeiras crônicas do século XVI) em populações associadas à entidade arqueológica Goya-Malabrigo, que poderia ser uma derivação da expansão meridional dos Arawak. Finalmente, o estudo da dispersão dos guaranis e os modos de interação com as populações locais foram abordados. Em suma, os avanços nas pesquisas da última década mostram um panorama mais complexo que integra a história indígena local a processos adaptativos gerais ocorridos ao longos das terras baixas sulamericanas.

\section{Palavras-chave: Aterros, Práticas mortuárias, Tecnologia cerâmica, Subsistência, Nordeste argentino}

\section{Introducción}

Los mayores cursos hídricos que surcan las Tierras Bajas del sur de Sudamérica -Pilcomayo, Bermejo, Paraguay, Paraná, Uruguay y Río de la Plata- han sido escenarios naturales privilegiados para el desarrollo de una larga historia indígena. Los numerosos rasgos culturales compartidos denotan una gran conectividad entre distintos grupos etnolingüísticos, una fluida transmisión de saberes, circulación de bienes y movimientos poblacionales a gran escala. Entre los caracteres ampliamente difundidos, se destacan las estrategias de ocupación en espacios susceptibles a las inundaciones causadas por la dinámica hidrometeorológica, la cual genera extensas áreas anegadas con una valiosa biodiversidad. Para la instalación en estos ricos ambientes, dominados por topografías planas y rodeados por las aguas, en la cuenca del Río de la Plata se construyeron desde el Holoceno medio numerosas estructuras monticulares de tierra, llamadas cerritos en la región. Estas estructuras conservan restos arqueológicos producto de actividades domésticas, extractivas, productivas y, en numerosos casos, funerarias. Las mayores concentraciones de montículos prehispánicos en las llanuras aluviales de la cuenca del Plata, se registran en el Alto río Paraguay (Schmidt 1912; Eremites de Oliveira 1996; Schmitz et al. 2004; Peixoto 2005), el Paraná Inferior (Bonomo et al. 2011a; Politis et al. 2011; Castiñeira et al. 2013), el Uruguay Inferior (Capdepont 2012; Castro 2017, 2018; Castro \& Castiñeira 2017; López Mazz 2018), las cuencas del río Tacuarembó (noreste de Uruguay; Gianotti 2016) y de las lagunas Merín-de los Patos (este de 
Uruguay y sureste del Brasil; Bracco et al. 2000; López Mazz et al. 2016; García 2017; Iriarte et al. 2017a; Milheira \& Gianotti 2018).

En la llanura aluvial del río Paraná, los cerritos conforman el registro arqueológico de mayor visibilidad y fueron identificados desde las primeras investigaciones arqueológicas que se desarrollaron en la región a fines del siglo XIX (p. ej., Lista 1878; Zeballos \& Pico 1878; Ameghino 1881). Sin embargo, y al igual que con los tesos de la isla fluvial de Marajó (Rossetti et al. 2008; Schaan 2012), las lomas de los Llanos de Mojos (Erickson 2000) o los sambaquís de la costa atlántica centro-sur del Brasil (Gaspar 2014), desde su reconocimiento, se ha debatido y propuesto una génesis natural (Frenguelli \& Aparicio 1923; Cione et al. 1977), antrópica (Zeballos \& Pico 1878; Torres 1911) o mixta (Lothrop 1932; González 1947; Lafon 1971). Estudios arqueológicos recientes en el Delta del Paraná (Bonomo et al. 2011a; Politis et al. 2011; Castiñeira et al. 2014; Loponte et al. 2016) han confirmado que las poblaciones indígenas que ocuparon el área durante el Holoceno tardío no solo se asentaron en lugares naturalmente elevados (albardones, médanos, espiras de meandros o crestas bioclásticas), sino que también transformaron las planicies fluviales mediante la construcción de montículos. En algunos casos, para erigir los cerritos fueron seleccionadas las superficies de geoformas originalmente positivas (Castiñeira et al. 2014), en tanto que en otros, los cerritos fueron levantados en las planicies mejor preservadas durante las fases de aguas altas (Castiñeira et al. 2017a). En las dos modalidades, la ingeniería constructiva implicó la selección de fangos, su acarreo desde áreas próximas o distales al lugar escogido para el asentamiento y la adición de materiales gruesos tales como tiestos y restos orgánicos, para favorecer la cohesión y perduración de las estructuras (Castiñeira et al. 2013).

Las investigaciones en el Delta Superior del Paraná han asociado una parte de los montículos del Paraná Inferior con sociedades con cierta complejidad o jerarquías sociales y con prácticas hortícolas a pequeña escala que se asignan a la entidad arqueológica Goya-Malabrigo (Politis \& Bonomo 2012, 2018a y b). Ambos aspectos ya habían sido sugeridos previamente en base a información etnohistórica o arqueológica (Serrano 1930; Ceruti, 2003). Sin embargo, solo recientemente se han generado nuevas evidencias con métodos actuales (p. ej., estudios de almidones y fitolitos, de macrorrestos vegetales obtenidos por flotación y microestratigrafía) que permitieron abordar estos temas a la luz de enfoques contemporáneos, los que ciertamente cambiaron el eje de la discusión sobre la ocupación prehispánica del Paraná Inferior y Medio.

Esta contribución resume los principales temas estudiados para conocer las poblaciones indígenas que a partir del Holoceno tardío ocuparon la llanura aluvial del Paraná Medio e Inferior. Nos enfocaremos especialmente en el estado actual de las investigaciones en el Delta Superior del Paraná que es el área en la que nuestro equipo desarrolla sus trabajos desde hace más de una década. Además de sintetizar la información ambiental y los principales antecedentes, abordaremos con mayor profundidad aquellos aspectos en los que más se avanzó en los últimos años: las modalidades de asentamiento, la economía, la tecnología cerámica y las prácticas mortuorias de Goya-Malabrigo y la expansión guaraní al área de estudio.

En la región se dio una intensa dinámica cultural en la que participaron, además de los grupos locales, los guaraníes y posiblemente los arawak, ambos descendientes de poblaciones que probablemente tuvieron su origen en la Amazonia pero que migraron y se expandieron más allá de los límites de esta cuenca. Hacia el sur los guaraníes alcanzaron el Delta del Paraná después de $c a$. 700 años ${ }^{14} \mathrm{C}$ AP, mientras que grupos de filiación arawak, probablemente vinculados con la génesis de la entidad arqueológica Goya-Malabrigo, podrían haber llegado previamente al Paraná Medio e Inferior, tal como lo propusieron Torres (1911), Nordenskiöld ([1916] 2009, [1930] 2017), Métraux (1934) y Serrano (1972). La diversidad de grupos étnicos y "parcialidades" afines que los primeros conquistadores europeos encontraron en el Paraná a principios del siglo XVI es el resultado de esta dinámica y el producto de procesos evolutivo/adaptativos y de trayectorias históricas particulares. 


\section{Ambiente}

La cuenca del Plata, con una extensión de $3.100 .000 \mathrm{~km}^{2}$, es el segundo mayor sistema fluvial de América del Sur. Los ríos Paraná, Paraguay y Uruguay son sus tres mayores colectores y corren predominantemente en sentido norte-sur, conectando desde regiones intertropicales hasta templadas (Soldano 1947; Bonetto 1986). En sus recorridos sin grandes barreras físicas, transportan no solo agua, sino también minerales y nutrientes para los suelos, lo que determina que funcionen como activos corredores de biodiversidad (Giraudo \& Arzamendia 2004). La sub-cuenca del Paraná es la más grande (ca. $2.600 .000 \mathrm{~km}^{2}$ ) y contribuye con el $77 \%$ del agua que descarga la cuenca del Plata, con un volumen de flujo cercano a los 500 millones $\mathrm{m}^{3}$ por año (Bonetto 1986; Drago 1990). El río Paraná posee una longitud de alrededor de $4.000 \mathrm{~km}$, solo superada en Sudamérica por el Amazonas. Nace en la Serra dos Pireneus en Brasil y desemboca con un delta que avanza alrededor de $60 \mathrm{~m}$ anuales sobre el Río de la Plata (Bonetto 1986; Codignotto \& Kokot 2005). Su régimen hidrológico alterna fases de inundaciones en diferentes estaciones y con distinta frecuencia, intensidad y duración (de pocas semanas a más de un año), destacándose las crecidas extraordinarias que cubren gran parte de la tierra emergida en su llanura aluvial (Malvárez 1997).

El Paraná se define como un macrosistema fluvial (Neiff 1990), conformado por una variedad de regiones con ambientes bien diferenciados (Figura 1) y contrastantes que incluyen selvas, desiertos de montaña y sabanas. Se caracteriza por su diversidad geológica y climática, con gradientes de temperaturas, precipitaciones y altitud con respecto al nivel del mar (Iriondo et al. 2007). Los bosques que se extienden por sus márgenes mantienen características ecológicas propias a pesar de los distintos ambientes que atraviesa el río, lo cual permite el movimiento de la fauna siguiendo estas franjas arbóreas adyacentes a los cursos. Durante los desbordes, los mamíferos tienen desplazamientos del orden de cientos de kilómetros, mientras que los peces y las aves migran por distancias superiores a los $1.000 \mathrm{~km}$ (Neiff 2005). La dirección del flujo de las aguas explica la riqueza y diversidad específica del ecosistema deltaico (Burkart 1957; Malvárez 1997).

El sector del río Paraná que surca el territorio argentino ( $c a .1 .930 \mathrm{~km}$ de extensión) bordea, de norte a sur, las provincias de Misiones, Corrientes y Entre Ríos (margen izquierda) y las provincias de Chaco, Santa Fe y Buenos Aires (margen derecha) y posee una importante biodiversidad. En los bosques que cubren las islas y orillas del Paraná encontramos las siguientes especies: Cecropia adenopus, Croton urucurana, Solanum mauritianum, Peltophorum dubium, Pouteria gardneriana, Myrsine laetevirens, Pithecellobium multiflorum, Enterolobium contortisiliquum, Nectanda falcifolia, Terminalia triflora, Syagrus romansoffiana, Salix humboldtiana, Erythrina crista-galli, entre otras (Cabrera 1953). En la fauna se destacan distintos mamíferos (Blastocerus dichotomus, Ozotocerus bezoarticus, Mazama guazoupira, Hydrochoerus hydrochaeris, Myocastor coypus, Chrysocyon brachyurus, Panthera onca, Oncifelis geoffroyi, entre muchos otros), aves (distintas familias, por ejemplo, Phalacrocoracidae, Ardeidae, Anatidae, Podicipedidae, Rallidae, Psittacidae), reptiles (p. ej., Tupinambis merinae y Caiman latirostris), moluscos (Diplodon sp., Ampularidae) y, sobre todo, una gran abundancia de peces con alrededor de 300 especies de los órdenes Characiformes y Siluriformes (López 2001). El curso medio del Paraná y parte de su curso inferior son las áreas pesqueras más productivas de acuerdo a los volúmenes de captura, con una ictiomasa promedio $1.160 \mathrm{~kg} / \mathrm{ha}$ (Bonetto 1998).

El curso del río Paraná ha sido dividido según diversos criterios (Soldano 1947; Bonetto 1986; Neiff 1990; Giraudo \& Arzamendia 2004). En este capítulo usaremos la división más usual en la hidrografía y arqueología de Argentina: el Alto Paraná, desde su nacimiento hasta la confluencia con el río Paraguay; el Paraná Medio, desde allí hasta el inicio del Pre-Delta en la localidad de Diamante en la provincia de Entre Ríos; y el Paraná Inferior que está constituido principalmente por el complejo deltaico hasta la desembocadura en el Río de la Plata (Drago 1990). El delta es un conjunto de islas fluviales, surcadas por numerosos cursos y cuerpos de agua, con una extensión de $320 \mathrm{~km}$ de largo por un promedio de $60 \mathrm{~km}$ de ancho. Clásicamente se ha dividido en Delta Superior, Medio e Inferior. Los dos primeros poseen características similares al Paraná Medio, mientras que en el Delta Inferior se distinguen, además de las geoformas deltaicas, otras de origen marino, como antiguos cordones arenosos, lagunas litorales y canales de marea (Bó 2006). 

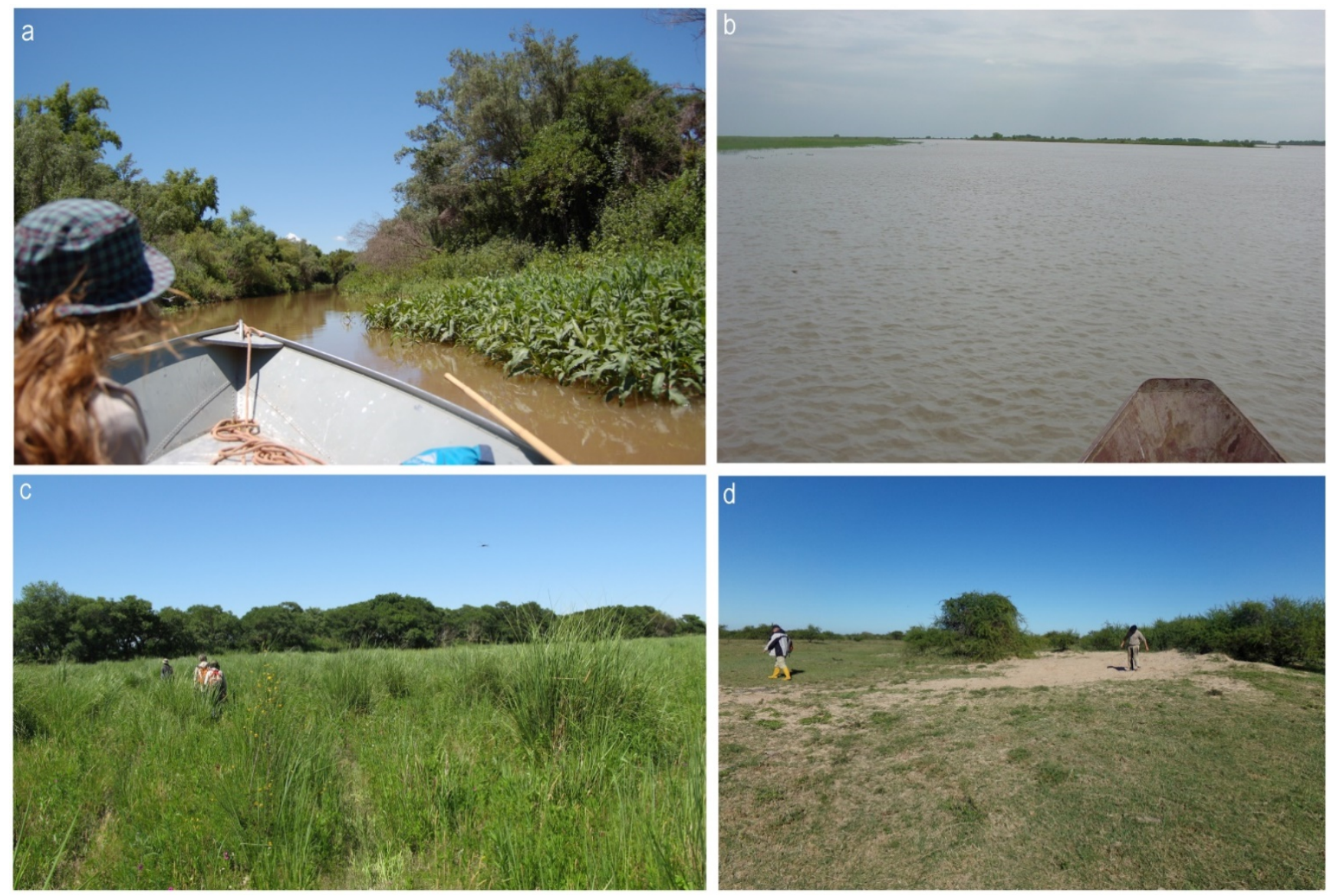

Figura 1. Distintos ambientes del río Paraná relevados durante las prospecciones arqueológicas. a. $\mathrm{A}^{\circ}$ La Manga con su selva en galería (departamento Diamante); b. laguna Grande (Victoria); c. bajo con pastizales y albardón del sitio arqueológico Co. de las Pajas Blancas 1 (San Jerónimo) y d. cadena de médanos (sitio arqueológico Médano La Sonrisa, Victoria).

La mayor parte de la evolución del complejo deltaico ocurrió durante el Holoceno y estuvo condicionada por los cambios climáticos y del nivel del mar, la topografía del sustrato y el aporte sedimentario de los ríos Paraná y Uruguay (Cavallotto et al. 2005). El desarrollo de este complejo consta de cinco fases: 1) un período fluvial-eólico representado por la planicie de inundación pleistocénica; 2) una ingresión marina holocénica que en su máximo nivel en el 6000 años ${ }^{14} \mathrm{C}$ AP desarrolló una gran barrera de arena, el delta del río Uruguay y deltas tributarios menores; 3) una fase de lagunas, estuarios y depósitos de regresión bien desarrollados; 4) una fase estuárica con depósitos de marea extensivos en el área central y 5) el período fluvial actual, con depósitos de canal y deltaicos, cuya dinámica está dominada por los regímenes de los ríos Paraná, Uruguay y Gualeguay, mareas e inundaciones producidas por el viento sudeste (Iriondo 2004, 2007).

\section{Antecedentes}

Los primeros estudios en el Paraná Inferior y Medio identificaron materiales asignados a lo que hoy se conoce como entidades arqueológicas de la región: Guaraní y Goya-Malabrigo. Las primeras referencias éditas son de la primera mitad del siglo XIX y corresponden a urnas corrugadas con tapa y vasijas polícromas guaraníes (Muñiz 1825; Sastre [1856] 2010). Luego, Zeballos y Pico (1878) excavaron el sitio denominado Túmulo de Campana (Figura 2) y propusieron que se trataba de un montículo artificial. Allí recuperaron alfarería con modelados zoomorfos de aves, mamíferos y moluscos, apéndices que luego serían empleados como uno de los rasgos diagnósticos de Goya-Malabrigo. Las investigaciones de Juan Bautista Ambrosetti (1894) en el arroyo Pehuajó en Goya, sobre el Paraná en Corrientes, mostraron la gran dispersión areal del estilo cerámico asociado con estos característicos modelados zoomorfos. También, se identificaron materiales en el 
Delta Inferior cuya asignación arqueológica no es tan clara como en las dos entidades anteriormente mencionadas (véase por ejemplo Torres 1911).

Desde fines del siglo XIX y, sobre todo, a comienzos del XX, Torres (1911) excavó varios montículos aislados en el Delta Inferior, y al igual que Lista (1878), consideró que habían sido levantados por los indígenas para evitar las recurrentes inundaciones en la zona. Torres atribuyó las diferencias observadas en la decoración de la alfarería a diferentes etnias de tiempos históricos. Vinculó los apéndices zoomorfos a los arawak meridionales, conocidos como guanás. Cabe destacar que el padre jesuita Sánchez Labrador (1910 en Cardoso de Oliveira 1960, p. 25), mencionó que los guanás en realidad se autodenominan chanás, etnónimo también utilizado por los grupos indígenas de los cursos medio e inferior del Paraná e inferior del Uruguay.

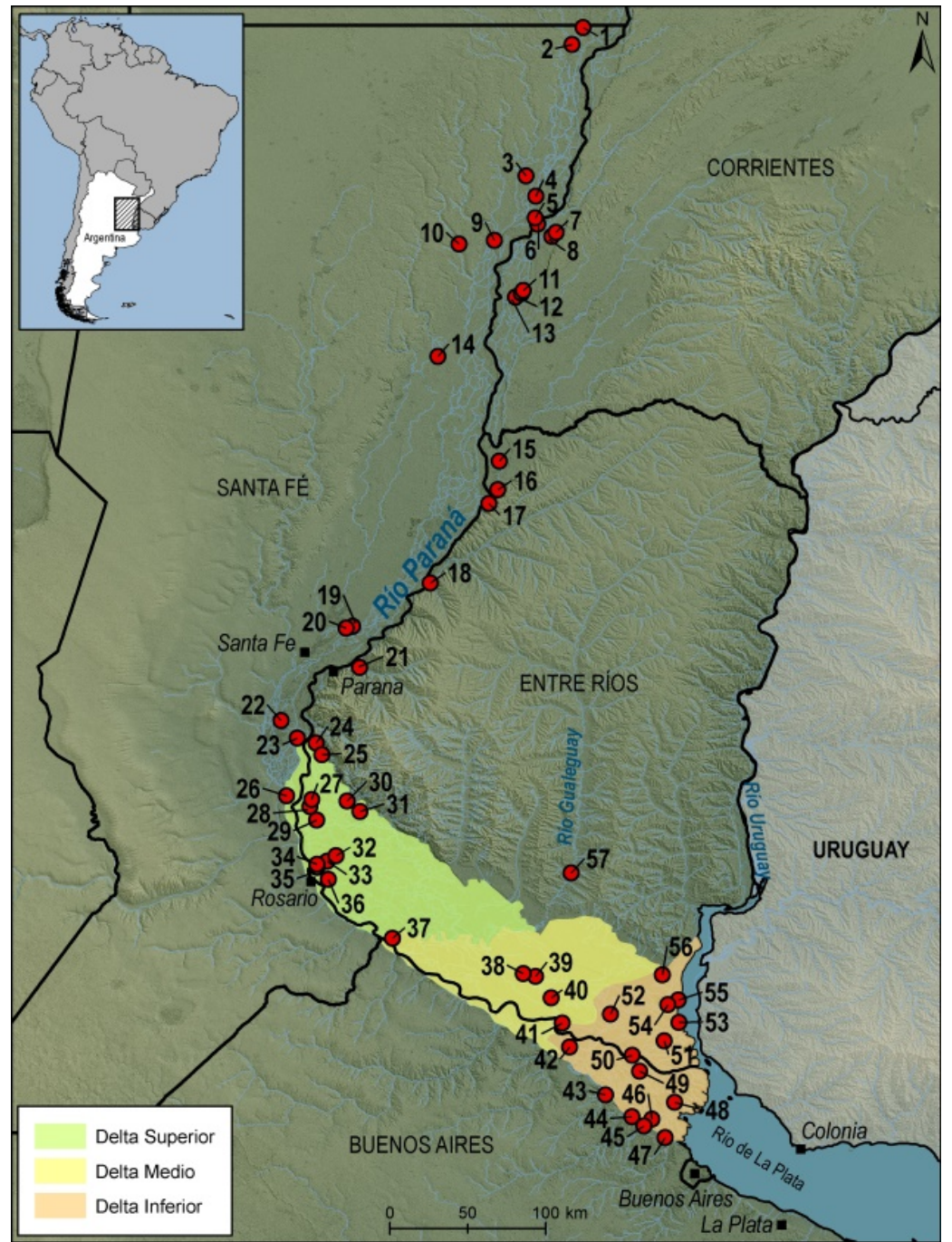

Figura 2. Principales sitios arqueológicos mencionados en el texto. 1. Co. Aguará; 2. Barrancas del Paranacito; 3. Paraná Miní 1; 4. Río Salado Coronda; 5. Isla del Indio; 6. Paso del Tala; 7. Paradero Pehuajó; 8. Túmulo del Usuró; 9. $\mathrm{A}^{\mathrm{o}}$ Aguilar; 10. Localidad Malabrigo; 11. Los Bananos; 12. Los Chanchos; 13. El Nene; 14. La Lechuza; 15. Las Mulas I; 16. A ${ }^{\circ}$ Arenal; 17. Brazo Largo; 18. La Palmera II; 19. Isla Cementerio; 20. El Capón 2; 21. Las Conchas o Quinta de Pérez Colman o VU 5; 22. Las Tejas; 23. Co. de las Pajas Blancas 1; 24. Co. Tapera Vazquez; 25. Co. Farall; 26. Fuerte Sancti Spíritus; 27. Co. Barrancas; 28. Laguna de los Gansos 1 y $2 ; 2$ 29. Los Dos Cerros 1 y $2 ; \mathbf{3 0}$. Co. Los Cardos; 31. Los Laureles; 32. Co. Puesto Acosta; 33. Co. El Durazno; 34. Co. El Castaño 1 y $2 ; 35$. Los Tres Cerros 1 y $2 ; \mathbf{3 6}$. Co. Grande de la Isla Los Marinos; 37. Co. Grande del Paraná Pavón; 38. La Argentina; 39. Paraná Ibicuy 1; 40. Cementerio de Mazaruca o Paraná Ibicuy $3 ;$ 41. Isla Lechiguanas I; 42. Isla Talavera BD-S1; 43. Túmulo de Campana; 44. Anahí; 45. $\mathrm{A}^{\mathrm{o}} \mathrm{La}$ Glorieta; 46. $\mathrm{A}^{\mathrm{o}}$ Malo; 47. $\mathrm{A}^{\mathrm{o}}$ Sarandí; 48. $\mathrm{A}^{\mathrm{o}}$ Fredes; 49. Túmulo I del Paraná Guazú o El Cerrillo; 50. Túmulo II del Paraná Guazú; 51. Túmulo I del Brazo Gutierrez; 52. Don Santiago; 53. Túmulo I y II del Brazo Largo; 54. Co. Lutz; 55. Rodeo Viejo de la Nena; 56. Co. Mayor y 57. Laguna del Negro.

El esquema de desarrollo cultural de Torres (1911) para el delta fue luego refinado por Outes (1918a), quien distinguió, desde el Paraná Medio hasta la isla Martín García en el Río de la Plata, tres grupos sucesivos en base a la cerámica y otros elementos. El primero de los grupos tenía una alfarería "muy simple" y "primitiva" con escasos ejemplares incisos o pintados asociados con instrumentos de hueso e inhumaciones en terrenos elevados, "al parecer túmulos". El segundo grupo sería constructor de montículos, también usados para inhumaciones, y elaboraba cerámica con decoraciones plásticas de seres humanos y animales, escasos instrumentos de piedra y herramientas en hueso. Por último, el tercero era el guaraní con grandes urnas funerarias polícromas o corrugadas, hachas de piedra pulida y escasos instrumentos óseos. Este esquema cultural tuvo una fuerte aceptación entre los distintos investigadores que estudiaron durante las décadas siguientes la arqueología del Paraná. 
En 1923 Frenguelli y Aparicio dieron a conocer los resultados de las excavaciones en elevaciones con forma de lomas localizadas fuera del delta, en las inmediaciones del río Malabrigo en la margen derecha de la llanura aluvial del Paraná (Santa Fe). Estos investigadores plantearon que no serían túmulos sino médanos consolidados sobre los que se asentaron los indígenas para protegerse de las inundaciones (Frenguelli \& Aparicio 1923). El detallado trabajo geológico de Frenguelli fue muy influyente para los estudios posteriores sobre montículos y consolidó la idea de que las ocupaciones indígenas habían ocurrido solo sobre elevaciones naturales.

Para la misma época, las excavaciones de varios sitios arqueológicos brindaron resultados relevantes para discutir tendencias regionales. En 1923, Gaggero y Fernández del Museo de La Plata, excavaron un pequeño montículo circular en el Delta Inferior, el Túmulo II de Brazo Largo, y sugirieron que era de origen cultural (véase Politis et al. 2017). En 1925 el arqueólogo estadounidense Lothrop (1932) excavó tres sitios en el Delta Inferior y en el borde de la llanura aluvial a los que, en base a correlaciones etnohistóricas, los atribuyó a una aldea guaraní (sitio Arroyo Malo), a un asentamiento de los querandíes (sitio Arroyo Sarandí) y a otro de los chaná-mbeguá o chaná (sitio El Cerrillo). Estos aportes fueron generando un modelo regional que reconocía la variabilidad cultural del río Paraná.

En 1939, mucho antes de doctorarse en arqueología en la Universidad de Columbia, González (1947) realizó su primera excavación en el sitio arqueológico Cerro Grande del Paraná Pavón, que se diferencia de las elevaciones de origen eólico reconocidas por Frenguelli (Frenguelli \& Aparicio 1923) y de los montículos con posible agregado intencional de sedimentos descriptos por Torres (1911). Al igual que Lothrop (1932) planteó que el sitio se había formado a partir de una pequeña elevación natural que fue aumentando paulatinamente su volumen por depositación natural y en menor proporción por el aporte humano. En 1946 Gaspary (1950) inició sus investigaciones en las islas frente a la ciudad de Rosario, donde excavó el Cerro Grande de la Isla Los Marinos, un montículo artificial erigido sobre una elevación natural del terreno. Este autor asoció una hondonada inmediatamente adyacente al cerro, con el área de extracción de los sedimentos utilizados para la construcción. Además, extrajo una importante cantidad de esqueletos humanos, varios de ellos pintados con ocre rojo (Kozameh et al. 2018).

Basado en sus investigaciones de largo plazo en el Nordeste Argentino, pero también en Rio Grande do Sul en Brasil, Serrano $(1950,1972)$ estableció las "líneas fundamentales" del pasado prehispánico de los ríos Paraná y Uruguay, modelo regional que estuvo vigente hasta la década de 1970. Excavó varios sitios arqueológicos de relevancia como Las Tejas, Las Conchas y Las Mulas (Figura 2). Con la introducción de algunos conceptos de la escuela histórico-cultural norteamericana, elaboró un modelo explicativo sobre el desarrollo pre y poshispánico del Nordeste (véase Escudero et al. 2011), basado principalmente en las variaciones espaciales de la cerámica y la ubicación de distintas etnias en los siglos XVI y XVII. Propuso una ocupación cerámica inicial de la "Cultura Entrerriana" que más tarde recibiría en el Paraná y el Bajo Uruguay los aportes de grupos de origen amazónico más avanzados y que habían generado una nueva forma cultural que llamó "Ribereños Plásticos”. Si bien planteó que se mantenían las características básicas de la alfarería previa, con dichos aportes -que atribuyó a los arawak- se le sumarían las representaciones artísticas de animales (apéndices zoomorfos sobre todo de aves y mamíferos). Este autor consideraba que los cambios en las características de la alfarería reflejaban la difusión de ideas innovadoras, la adquisición de técnicas vía transmisión femenina y la dispersión de poblaciones que llegaban por oleadas migratorias desde zonas vecinas. En su clasificación general de los indígenas de la Argentina (Serrano 1941), describió a estas poblaciones del Paraná como "agricultores intermedios" que poseían una "organización con grandes cacicazgos, al menos regionales". Este autor también resumió la discusión sobre la existencia de cerritos, y si bien no desconocía la existencia de montículos construidos en el delta, siguiendo los estudios de Frenguelli, pensó que se trataría en la mayoría de los casos (sobre todo en el Paraná Medio) de restos de médanos consolidados o albardones, sin modificaciones significativas, sobre los cuales se asentaron las poblaciones indígenas (Serrano 1950).

Desde una perspectiva histórico-cultural más ecléctica, Lafon (1971) desarrolló investigaciones en el Paraná Medio e Inferior y el Uruguay Inferior. Reflexionó críticamente sobre la metodología utilizada en las 
excavaciones de sitios sobre terrenos elevados y la necesidad de basar las inferencias en datos obtenidos sistemáticamente. Fue bastante escéptico con respecto al origen cultural de los cerritos del delta, aunque reconoció su sobreelevación antrópica por acreción. Una observación interesante de Lafon (1971, p. 131) fue que atribuyó algún tipo de horticultura ("primitivos agricultores paleoamazónicos"), a lo que luego se llamó Goya-Malabrigo. Esto de alguna manera anticipaba la confirmación posterior de la existencia de horticultura en estas poblaciones.

Luego de su participación en el grupo encabezado por Cigliano del Museo de La Plata en el río Uruguay y en el Río de la Plata, Caggiano (1984) centró sus investigaciones en el Delta y el Uruguay inferiores, donde abordó varios sitios, como Isla Lechiguanas I, Paraná Ibicuy, Rodeo Viejo de La Nena, Don Santiago y El Potrero. A partir de la elaboración de listados sistemáticos con la fauna de los sitios, del análisis de las pastas cerámicas y de los estilos decorativos amplió la caracterización de algunas de las categorías de Serrano, por ejemplo la de los "Ribereños Plásticos" y la "Ibicueña" (a la que asoció con un tipo de asentamiento monticular). En base a excavaciones de esos nuevos sitios ubicados sobre albardones, paleoalbardones o bordes de bañados y a varios fechados de ${ }^{14} \mathrm{C}$, Caggiano (1984) buscó establecer un cuadro cronológico que integrara la variabilidad regional en etapas, tradiciones, culturas y facies.

A mediados de la década de 1980, Ceruti (1986) planteó la existencia de "dos tipos culturales": Cancha de Luisa y Goya-Malabrigo en base a sus trabajos en el Paraná Medio. Posteriormente, propuso un modelo de desarrollo cultural que integraba dentro de un marco ecológico, las entidades culturales propuestas, de las cuales en este capítulo nos centraremos en Goya-Malabrigo (Ceruti 2003). Esta entidad fue caracterizada por un estilo cerámico distintivo (apéndices zoomorfos, campanas, vasijas globulares cerradas, cucharas, entre otros), y por la ocupación de las islas y la planicie de inundación del Paraná Medio e Inferior junto con ambas márgenes del Uruguay Inferior, desde $c a .2000$ años ${ }^{14} \mathrm{C}$ AP hasta los primeros siglos de la colonia. Como lo han expresado numerosos autores (Aparicio 1936; Gaspary 1945; González 1947; Serrano 1950; Rodríguez \& Ceruti 1999; Ceruti 2003; Bonomo et al. 2011a), Goya-Malabrigo (o su homóloga Ribereños Plásticos) sería la expresión arqueológica de los indígenas del siglo XVI y XVII conocidos genéricamente con el etnónimo chaná-timbú que reune a los timbú, chaná, mbeguá, caracaraes, corondás, colastinés, quiloazas, entre otros. Posteriormente, se le agregaron otros rasgos a esta entidad arqueológica (Politis \& Bonomo 2012, 2018a), tales como la construcción de montículos, un intenso uso de la arcilla en las diferentes dimensiones de la cultura material y una economía mixta de caza, pesca, recolección con una horticultura de maíz, poroto y zapallo.

Desde principios de 1990, Acosta y Loponte han realizado investigaciones en un microsector del Paraná Inferior, los Bajíos Ribereños Meridionales, continuando el estudio de los sitios reportados por Lafon y agregando algunos nuevos, pero sin identificar en un principio la presencia de montículos. Incluso plantearon que los cerritos de Entre Ríos eran en realidad albardones naturales (Acosta \& Loponte 2008), incluyendo más tarde dentro de esta categoría a sitios clásicos en la literatura como el Túmulo de Campana (Loponte \& Acosta 2015). Luego de ampliar su área de investigación al sector entrerriano del Delta Inferior, plantearon la existencia de sitios sobre formaciones medanosas, reconociendo que en su altura pudieron intervenir factores antrópicos. Recientemente identificaron cerritos (Loponte et al. 2016) lo que apoya las propuestas previas de Bonomo et al. (2011a), Politis et al. (2011) y Castiñeira et al. (2013). Desde una perspectiva evolutiva propusieron para el Delta Inferior dos "linajes arqueológicos" sobre la base de "paquetes de rasgos" que tienen en cuenta la incidencia de los peces en la dieta, el grado de fragmentación de las carcasas, la forma de los tembetás o de los botones labiales, el empleo de materia prima lítica y la proporción de cerámica incisa (Loponte et al. 2012; Acosta, et al. 2013).

Desde la década de 1990, desde la Universidad de Rosario (UNR), se llevan a cabo investigaciones en el Delta Superior y en la margen derecha del Paraná Medio (provincia de Santa Fe). En la primera de las áreas se destaca la excavación del Cerro El Castaño 1 y 2 por Nóbile (2002) y Cornero (2009), mientras que en la segunda se investigó exhaustivamente el sitio La Lechuza (Cornero et al. 2007). Campos (2001) realizó estudios sedimentarios y de distribución de los materiales arqueológicos del sitio, concluyendo que se trata de una estructura elevada con aporte antrópico. También sobre la margen santafesina, Pérez Jimeno (2007) realizó 
investigaciones arqueológicas en el Paraná Miní y analizó la arqueofauna y la tecnología ósea de los sitios Barrancas del Paranacito y Cerro Aguará (Figura 2). Para esta misma zona deben mencionarse los trabajos de Cocco (2003) en el Bajo de los Saladillos, de Feuillet Terzaghi (2009) y Sartori (2015a; Sartori et al. 2013) en la cuenca inferior del río Salado y media e inferior del río Coronda, de Ottalagano $(2009,2013)$ en el Paraná Medio, continuando con la investigación de algunos de los sitios detectados por Ceruti (Ottalagano et al. 2015), de Escudero y Letieri (Escudero \& Feuillet Terzaghi 2002; Letieri \& Alonso 2004) al sur de Rosario, de Rocchietti y de Grandis (Rocchietti et al. 1997) en islas del Delta Superior y de Kozameh (2009; Kozameh \& Brunás 2013; Kozameh et al. 2018) con la colección osteológica del Cerro Grande de la Isla de Marinos.

A partir de 2007, desde el Centro de Estudios Interdisciplinarios en Antropología de la UNR, el equipo dirigido por Barboza y Píccoli (Barboza \& Píccoli 2013; Barboza 2014; Píccoli 2014; Píccoli \& Barboza 2018) viene desarrollando investigaciones arqueológicas en la margen izquierda del Paraná Medio (Corrientes). Realizaron estudios de colecciones de museos, prospecciones sistemáticas extensivas que incluyeron recolecciones superficiales, sondeos en sitios como Los Chanchos, El Nene y Paso del Tala, y la excavación del sitio Los Bananos (Figura 2). Sus trabajos, están dirigidos a la reconstrucción de los paisajes arqueológicos a partir del estudio de los procesos y formas de apropiación del espacio. Recientemente presentaron además el estudio de la colección Spinelli proveniente de varios sitios de la provincia (Píccoli \& Barboza 2018).

Desde 2006, los autores de este capítulo iniciaron sus investigaciones en el Delta Superior y su llanura adyacente. Como producto de los trabajos de campo, en los que se recorrieron más de $1.000 \mathrm{~km}$ en diferentes cursos y cuerpos de agua, se relevaron 84 sitios arqueológicos, de los cuales 25 se encuentran en el sector de llanura y 59 en el de islas; entre estos últimos 37 son montículos (Figura 3). Se retomaron las investigaciones en sitios clásicos de la arqueología del Paraná como son el Cerro Grande de la Isla Los Marinos y el Cerro de las Pajas Blancas 1 y se estudiaron antiguas colecciones de sitios caracterizados por sus excavadores como montículos del Delta Inferior, tales como el Túmulo de Campana, Túmulos I y II del Paraná Guazú, Túmulos I y II del Brazo Largo, Túmulo I del Brazo Gutiérrez, entre otros. Para evaluar el potencial arqueológico del área, se sondearon más de 30 sitios y se realizaron excavaciones sistemáticas en ocho de ellos: Cerro Tapera Vázquez (CTV), Laguna de los Gansos 1 y 2 (LDLG1 y 2), Los Tres Cerros 1 y 2 (LTC1 y 2), Cerro Farall (CF), Laguna del Negro y Cerro de las Pajas Blancas 1 (Figura 2; Bonomo et al. 2011b, 2016; Politis et al. 2011; Apolinaire 2017). Como se desarrollará en las páginas subsiguientes, los estudios geoarqueológicos (Castiñeira et al. 2014, 2017a y b), bioarqueológicos (Scabuzzo et al. 2015; Ramos van Raap 2018a, b), cerámicos (Di Prado 2015, 2016; Castro 2017; Silva 2017), faunísticos (Bastourre 2014; Bonomo et al. 2014, 2016; Apolinaire et al. 2016) y arqueobotánicos (Bonomo et al. 2011c; Colobig et al. 2015, 2018) proporcionaron un conjunto de datos novedosos que permitieron importantes avances en el conocimiento de las poblaciones indígenas del Delta Superior y de los caracteres regionalmente compartidos.

Como se ha resumido antes, además de las entidades Goya-Malabrigo y Guaraní, se han detectado otras expresiones arqueológicas, que no se incluyen en ninguna de estas dos. En un principio, una de las primeras en ser definidas fue la Cultura Entrerriana (Serrano 1972, p. 17) caracterizada como una "cultura de pescadores y cazadores, en posesión de una alfarería de formas simples, lisa o decorada pero sin aditamentos zoomorfos". Dentro de ésta se propusieron tres facies: Sarandí, Salto Grande (en el río Uruguay Medio) e Ibicuy; esta última es la expresión más definida en el delta (véase también Caggiano 1984 y Politis et al. 2017). La facie Ibicuy comparte muchos atributos con Goya-Malabrigo (construcción de cerritos, técnicas y motivos en los diseños de la alfarería, instrumental de hueso, gran parte de las prácticas mortuorias), pero básicamente no presenta los modelados zoomorfos tridimensionales, las siluetas bidimensionales ni las campanas de alfarería que son tan características de Goya-Malabrigo. Parece además haber algunas diferencias menores en la subsistencia y en el patrón de asentamiento. Ceruti (2003) también definió Cancha de Luisa para el Paraná Medio, cuyas características serían una cerámica de espesor delgado con pintura roja positiva, bordes incisos y recortados muy simples y escasa proporción de tiestos con decoración de punto simple o de línea. Cancha de Luisa ocuparía las lomadas eólicas del río Paraná, y la llanura próxima en cotas intermedias, y tendría una subsistencia diversificada con recursos balanceados entre los de origen fluvial y los terrestres de las llanuras altas. En 
términos cronológicos sería anterior y contemporánea a Goya-Malabrigo, y el contacto se habría producido según Ceruti (2003, p. 115) entre 1250 y 1150 años ${ }^{14} \mathrm{C}$ AP. Sin embargo, aún no están claras estas relaciones y tanto la Cultura Entrerriana como Cancha de Luisa no han sido abordadas sistemáticamente en la discusión actual de la arqueología regional.
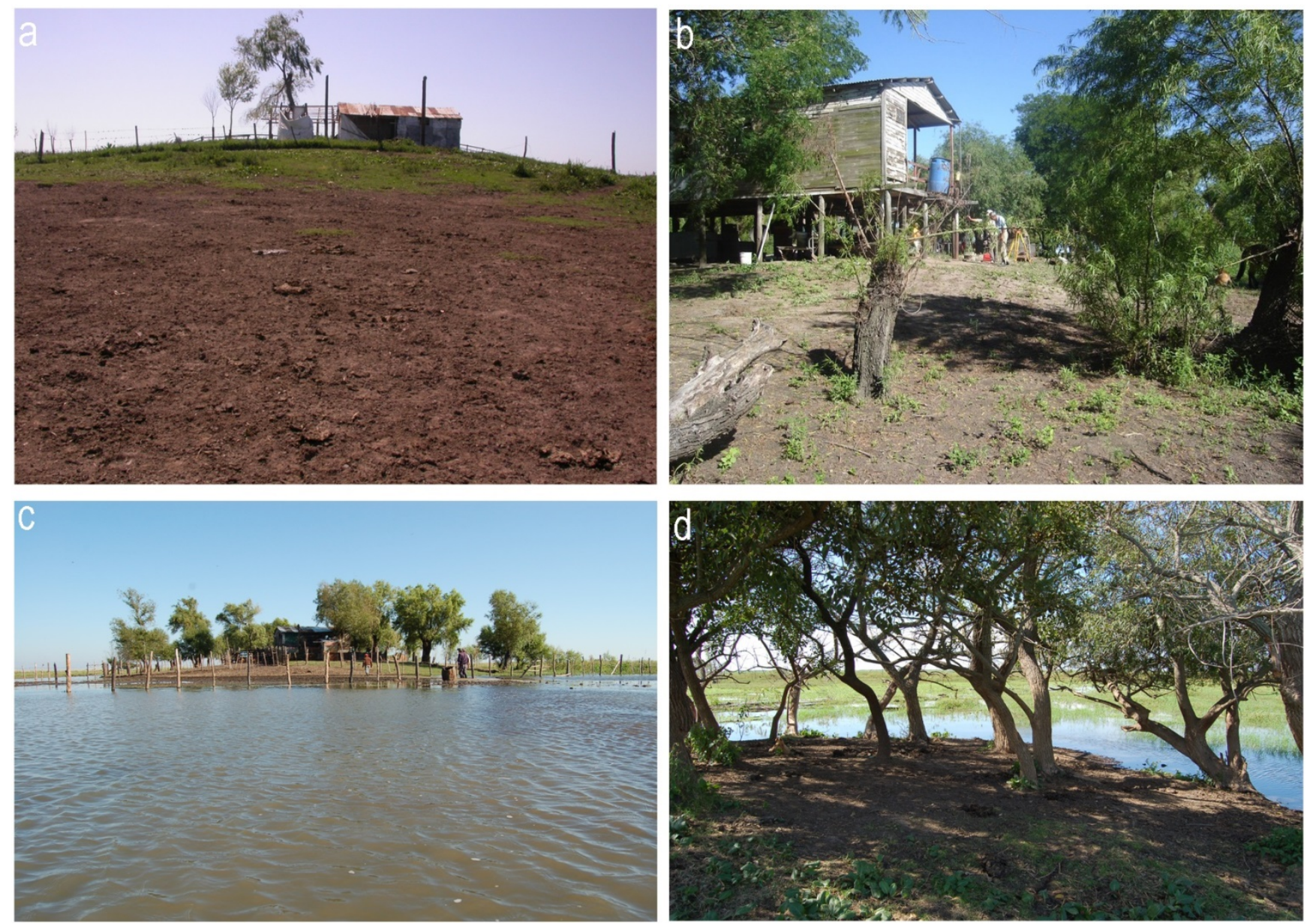

Figura 3. Estructuras monticulares relevadas en el Delta Superior del Paraná. a. Co. El Durazno; b. Co. Tejeira; c. Co. de Vázquez y d. Co. Cortada Pellegrini. Nótese que los puestos actuales continúan utilizando los cerritos prehispánicos para ocupar este ambiente anegadizo. Las fotos c y d fueron tomadas durante la inundación de abril de 2011.

\section{La ocupación Goya-Malabrigo}

\section{Construcción del paisaje}

Del apartado anterior se desprende que se han propuesto distintas alternativas para explicar la génesis de los montículos del Paraná: eventos masivos de construcción, el crecimiento por acreción derivado de eventos sucesivos de ocupación humana, el aprovechamiento de médanos o de albardones erosionados y la combinación de elevaciones naturales basales con acumulaciones antrópicas suprayacentes. En general se reconoce que los montículos son una adaptación especializada para ocupar espacios inundables, aunque como es sabido no todos ellos tienen el mismo origen y desarrollo, ya que responden a procesos culturales y naturales distintos.

Las dataciones más tempranas para Goya-Malabrigo en el Paraná se registran en torno a 2050 años ${ }^{14} \mathrm{C} \mathrm{AP}$ en el sitio Arroyo Aguilar II, localizado en el curso medio de este río (Echegoy 1994). De acuerdo con las 43 edades radiocarbónicas obtenidas en 14 sitios arqueológicos, la ocupación del Delta Superior también habría comenzado a ser poblado. Las evidencias más tempranas de la construcción de cerritos en el área fueron obtenidas en la localidad arqueológica Los Dos Cerros (LDC), la cual se caracteriza por la presencia de dos 
estructuras monticulares, una de las cuales, LDC1, muestra en sus depósitos basales los comienzos del proceso constructivo en torno a los 1950 años ${ }^{14} \mathrm{C}$ AP. Estas estructuras se encuentran a escasos $3 \mathrm{~km}$ de la localidad arqueológica Laguna de los Gansos (LDLG), donde se registraron eventos ocupacionales y entierros humanos en un albardón con cronologías de ca. 1700 y 500 años ${ }^{14} \mathrm{C}$ AP (Bonomo et al. 2016; Castiñeira et al. 2017a). En los ambientes isleños del delta las estructuras de tierra fueron erigidas para establecer áreas residenciales donde se llevaron a cabo actividades domésticas, hortícolas y funerarias (véase en detalle de esto último en el apartado siguiente). Entre otras actividades, se confeccionaron y usaron recipientes cerámicos, se utilizaron herramientas óseas y líticas, se cocinaron alimentos en fogones y se descartaron los huesos de los animales consumidos en basureros. Por ejemplo, el incremento de fitolitos de zapallo y maíz en ciertas capas de LTC1 sugiere el acondicionamiento del espacio y/o cultivo de especies domesticadas (Sánchez et al. 2013).

Como se ha expresado desde hace tiempo (p. ej., Outes 1918a; Gaspary 1950; Serrano 1950; Caggiano 1984; Bonomo et al. 2011a) la génesis de los cerritos no es uniforme y tampoco pueden asignarse a una sola entidad arqueológica. Aunque se han reportado muchos cerritos relacionados con Goya-Malabrigo en los cursos inferiores de los ríos Paraná y Uruguay, la presencia de montículos también se ha detectado en sitios no atribuibles a esta entidad (p. ej., Túmulo II de Brazo Largo o Túmulo I y II del Paraná Guazú en el Delta Inferior), algunos de los cuales han sido asignados a la facie Ibicuy o Ibicueña (Serrano 1950; Caggiano 1984).

Dados los avances geoarqueológicos, podemos distinguir diferentes registros monticulares según el sistema de depositación dominante en su morfogénesis y evolución. Cuando la acumulación de sedimentos y materiales culturales fue intencional con el fin de elevar y consolidar una morfología monticular, estamos frente a un cerrito construido. En este sentido, es posible incluir a las estructuras monticulares cuya morfología es heredada de una geoforma natural, pero, en su desarrollo volumétrico, hubo participación de los agentes culturales, incorporando deliberadamente materiales orgánicos e inorgánicos y sedimentos antropogénicos (intencionalmente modificado con fines constructivos, sensu Eidit 1985). Ambos tipos de estructuras, pueden presentar complejos sistemas de depositación antrópicos, constituidos por una o más unidades litobiocronoestratigráfícas cuya heterogeneidad puede seguirse por varios centímetros (capas) o encontrarse interrumpida por delgadas lentes (p. ej., de tierra quemada, carbón, hematita) y/o elementos interfaciales (p. ej., crotovinas, fogones). Generalmente, se trata de construcciones con evidencias de prolongados eventos ocupacionales, en las que se suelen superponer posibles pisos de habitación termoalterados y con marcas de poste, y del desarrollo de múltiples actividades entre las que se incluye el mantenimiento periódico del cerrito. Por otra parte, la génesis de superficies elevadas del terreno puede ser consecuencia del modelado del paisaje por agentes naturales (p. ej., fluvial, eólico, marino). En este caso se registran ocupaciones en geoformas naturales, que pudieron o no recibir aportes antrópicos clásticos y/o bioclásticos. En el primer caso, en el desarrollo estratigráfico de las geoformas, interviene la acumulación de materiales descartados o abandonados (viviendas, cerámica, huesos, valvas, maderas), que incrementan la altura de la superficie y generan modificaciones fisicoquímicas en los depósitos durante el asentamiento (p. ej., cambios en el pH, aumentos del contenido orgánico y de los valores de P), pero, sin mediar la intencionalidad humana en la generación de tales modificaciones. En este sentido, algunas de las geoformas elevadas del delta, pueden incluir sedimentos antrópicos (Eidit 1985). En el segundo caso, cuando no hay aporte antrópico que eleve el terreno, y las evidencias se concentran en los primeros $\mathrm{cm}$ del horizonte superficial, estos sitios pueden ser clasificados como someros. Tienen escasa resolución estratigráfica y cronológica, debido a que la intensa actividad bioestratinómica y los procesos pedogenéticos generan asociaciones diacrónicas (véase Zárate et al. 2002).

Los montículos no solo modificaron la composición de los suelos y la topografía, sino también los patrones de la vegetación. En ellos predomina una asociación arbórea (Acacia caven, Erythrina crista-galli, Salix humboldtiana, Enterolobium contortisiliquum, Sapium haematospermun, Nectandra falcifolia, Sesbania virgata, Euphorbia lathyris, Solanum glaucophyllum y Lycium vimineum) que contrasta con los pastizales que los rodean (Brea et al. 2013).

En la planicie inundable del Paraná Inferior las dos geoformas naturales elevadas más reclamadas para su ocupación fueron los albardones rectilíneos y los cordones litorales arenosos. En el Delta Superior y de acuerdo 
a los relevamientos planimétricos de alta resolución con estación total y a los estudios geoarqueológicos se pudo establecer un variado patrón ocupacional. A modo de ejemplo, las estructuras de LTC1 y LTC2 refieren a la ocupación en cerritos construidos, al igual que en el caso de LDC1 y LDC2 y el Cerro Grande de la Isla de Marinos. Para estos asentamientos, se planificó un uso a largo plazo y por ello hubo una importante inversión de trabajo en sus etapas de construcción y mantenimiento. El sitio CF fue recientemente excavado y corresponde a un montículo emplazado sobre un albardón, cuya génesis está dada por la ocupación de una geoforma elevada sobre la cual se comenzaron los procesos constructivos de adición de sedimentos antrópicamente modificados, incluyendo el aprovisionamiento de tierra en áreas circundantes y el agregado de materiales de granulometrías más gruesas como tierras quemadas y núcleos de arenisca (Castiñeira et al. 2014). En el caso de CTV la ocupación también ocurrió sobre un montículo desarrollado sobre un albardón, pero que fue elevado por el descarte de materiales durante la ocupación (Bonomo et al., 2014). Por su parte los sitios LDLG1 y LDLG2 (Bonomo et al. 2016) y ejemplifican ocupaciones en un extenso albardón que periódicamente se ve afectado por las inundaciones. Estos asentamientos serían temporarios y de menor jerarquía, respecto a las estructuras monticulares contruidas en el área.

En suma, como ha sido planteado para Goya-Malabrigo, el patrón de asentamiento es complejo y muestra distintos tipos de sitio, con jerarquías diferentes (Politis \& Bonomo 2012) lo que denota una variabilidad de las estrategias de ocupación del ambiente deltaico consistentes con las variaciones periódicas del nivel del Paraná. A su vez esto muestra la existencia de un sesgo para el estudio de estos patrones según la topografía de los espacios utilizados. Los asentamientos residenciales principales localizados en los lugares más altos tendrán mayor posibilidad de preservarse, al contrario de lo que sucede con aquellos campamentos temporarios y áreas de actividades localizadas en zonas bajas sujetas a las continuas inundaciones.

\section{Los entierros humanos}

Para el Paraná Medio e Inferior existe un amplio registro bioarqueológico, el cual se conformó desde fines del siglo XIX hasta las investigaciones actuales (Zeballos \& Pico 1878; Torres 1911; Aparicio 1928; Lothrop 1932; González 1947; Gaspary 1950; Schmitz et al. 1972; Ceruti et al. 1980; Cornero \& Cocco 1995; Mazza 2010; Cornero 2016; Scabuzzo \& Ramos van Raap 2017). En los últimos años el estudio de los restos óseos humanos viene tomando protagonismo en la región $\mathrm{y}$, a partir de las distintas líneas de análisis bioarqueológicas, se está aportando a la reconstrucción de los modos de vida prehispánicos en el área (Cornero \& Puche 2007; Kozameh et al. 2007, 2018; Kozameh \& Brunás 2009; Mazza \& Loponte 2012; Cornero \& Rangone 2015; Del Papa et al. 2016; Ramos van Raap \& Bonomo 2016; Ramos van Raap 2018a; Ramos van Raap \& Scabuzzo 2018a; Scabuzzo \& Ramos van Raap, 2017, 2019; entre otros).

A partir de las excavaciones en los sitios LTC1 y LDLG2 del Delta Superior, se hallaron numerosos entierros humanos (Scabuzzo et al. 2015; Bonomo et al. 2016). Los análisis bioarqueológicos en estos dos sitios permitieron obtener información detallada sobre las modalidades de inhumación y otros aspectos del registro que, al ser contextualizada con los demás entierros humanos conocidos en la literatura para el Paraná Medio e Inferior, permiten abordar en profundidad las prácticas mortuorias y el tratamiento dado a los cuerpos en tiempos prehispánicos.

En el sitio LTC1, específicamente en la pendiente del montículo, se llevó a cabo la inhumación de una gran cantidad de individuos (NMI= 35), de todas las categorías etarias y de ambos sexos. Entre 850 y 570 años ${ }^{14} \mathrm{C}$ AP se utilizó el asentamiento para fines inhumatorios, coincidiendo con el desarrollo de distintas actividades domésticas. Se registraron entierros primarios simples de individuos adultos y adolescentes (Figura 4a, b) y paquetes funerarios simples y múltiples de individuos subadultos y adultos (Figura $4 \mathrm{~b}, \mathrm{c}$ ). A estas modalidades se les suma el hallazgo, en el área de inhumación, de huesos aislados (incluyendo porciones anatómicas articuladas) y de una acumulación ósea que corresponde a un número mínimo de tres individuos. Sin duda, el origen y los procesos que dieron lugar a la formación de los huesos aislados y la acumulación ósea es uno de los 
temas de interés en la bioarqueología del NEA debido a su registro en otros sitios arqueológicos (González 1947; Gaspary 1950; Mazza 2010; Ramos van Raap 2018b). A partir de los análisis realizados en LTC1, estos conjuntos óseos fueron interpretados como el resultado de la remoción de esqueletos previamente enterrados para conformar luego paquetes funerarios (Scabuzzo \& Ramos van Raap 2017). Con el fin de profundizar en los procesos de formación de los paquetes secundarios, los estudios bioarqueológicos incorporaron el análisis de las huellas antrópicas. A partir de estos estudios se identificó una gran cantidad de huellas de corte en distintos elementos óseos que conforman estos entierros. Según las características y ubicación de las huellas, éstas fueron vinculadas con diferentes actividades tales como el descarne, la desarticulación y el raspado (Scabuzzo \& Di Lorenzo, 2017). La manipulación de los cuerpos luego de la muerte no sólo se expresa en las prácticas recién mencionadas, sino también en la aplicación de pigmento rojo (hematita) en varios de estos entierros y de sedimento arcilloso mezclado con pigmento (Scabuzzo \& Ramos van Raap, 2017). El uso de pigmento se dio en los restos pertenecientes a individuos de diferentes edades y ambos sexos, inhumados tanto de forma primaria como en los paquetes funerarios, en ciertos elementos de la acumulación ósea y en los huesos aislados (Scabuzzo et al. 2015). En cuanto a las adherencias arcillosas, se realizaron análisis composicionales de las mismas y se los comparó con los sedimentos del cerrito y la cerámica hallada en el sitio. Los resultados indican que la arcilla aplicada sobre algunos entierros y en el engobe de la cerámica es la misma y que se diferencian composicionalmente de las que integran el sedimento constitutivo del montículo (Scabuzzo \& Ramos van Raap 2017).

En cercanía a varios de los entierros humanos de LTC1 fueron recuperados conjuntos de tiestos que formaban parte de contenedores cerámicos; éstos habrían tenido inicialmente un uso doméstico, para luego pasar a formar parte del acompañamiento de los entierros (Castro 2017; Castro \& Castiñeira 2018). Asimismo, un rasgo recurrente en varias de las inhumaciones es la presencia de capas de valvas por encima de los cuerpos o como concentraciones en sus cercanías, lo cual parece relacionarse con la preparación de los lugares de inhumación o con cierta delimitación de los sectores de entierro (Scabuzzo \& Ramos van Raap 2017). Por otro lado, un hallazgo de particular relevancia corresponde a los huesos de al menos un adulto contenidos en un fogón, detectado en la cima del montículo (Scabuzzo et al. 2015). Los fragmentos óseos de este contexto presentan distintos grados de termoalteración y algunos poseen pigmento rojo sobre su superficie. Junto con este conjunto y también dentro del fogón, se hallaron fragmentos de hueso de mamífero indeterminado de tamaño grande. El fechado radiocarbónico de $775 \pm 85$ años ${ }^{14} \mathrm{C}$ AP muestra la contemporaneidad de este evento de inhumación con los otros entierros del sitio (Bonomo et al. 2011a). Como una posible explicación se propuso que el individuo representado en tal registro habría sido enterrado inicialmente en el núcleo inhumatorio y, luego de un tiempo, fue exhumado, se seleccionaron algunos huesos, se los pintaron y se los colocó en el fogón (Scabuzzo \& Ramos van Raap, 2017). El registro de LTC1 se superpone cronológicamente con el del sitio LDLG2, donde fueron hallados dos entierros humanos con dataciones de 590 y 570 años ${ }^{14} \mathrm{C}$ AP. Uno de los entierros corresponde a un adulto inhumado de forma primaria. El otro, también de un adulto, consiste en la cintura pélvica y los miembros inferiores articulados, con el cráneo localizado sobre la pelvis; el torso y los miembros superiores estaban ausentes (Figura 4d). Este esqueleto se encontraba asociado con tiestos cerámicos, entre los que se destaca un apéndice zoomorfo (Bonomo et al. 2016).

Los entierros humanos recién descriptos se suman al amplio registro bioarqueológico conocido para el Paraná Medio e Inferior, que incluye sitios vinculados con Goya-Malabrigo y otros no relacionados con esta entidad. En cuanto a la cronología de las inhumaciones, los fechados radiocarbónicos disponibles las ubican entre ca. 2050 (Echegoy 1994) y 310 años ${ }^{14} \mathrm{C}$ AP (Caggiano \& Flores 2001). A partir de la recopilación bibliográfica y análisis sobre este registro (Ramos van Raap 2018b), se observa un sustrato común entre los grupos humanos con respecto a las formas de enterrar a los individuos y a que en la mayoría de los sitios los espacios mortuorios no se encuentran segregados totalmente de aquellos lugares destinados a las actividades domésticas. Una excepción la constituye el sitio monticular La Lechuza, que fue interpretado como un área exclusiva de inhumación vinculado con la entidad arqueológica Goya-Malabrigo (Cornero 2016). Esto último cobra relevancia, ya que es la única evidencia para Goya-Malabrigo de áreas formales de entierro. 
En cuanto a las modalidades inhumatorias registradas tanto en LTC1 y LDLG2 como en otros sitios del Paraná Medio e Inferior, se distinguen algunas particularidades. En relación con los entierros primarios, los individuos masculinos fueron principalmente enterrados en posición decúbito dorsal, como ya fue observado por Mazza \& Loponte (2012) para el área denominada "Humedal del Paraná Inferior". Por su parte, para los individuos femeninos fueron detectadas inhumaciones tanto en posición dorsal como ventral, y algunos en decúbito lateral. Un aspecto observado de forma recurrente es que los infantes y niños fueron hallados en paquetes funerarios, de forma aislada y en acumulaciones óseas. Sólo se describe un entierro primario de un infante en el sitio Isla Cementerio (Cocco et al. 2004). Por otro lado, la prolongación temporal de los rituales mortuorios y la manipulación practicada en los restos esqueletales no sólo se refleja en los paquetes funerarios (con selección de partes, huellas de cortes y aplicación de ocre), sino también en los esqueletos con gran parte de su cuerpo articulado, pero con determinadas regiones anatómicas ausentes y/o reubicación de algunos huesos. Esto último, además de registrarse en LDLG2 (Bonomo et al. 2016), fue observado en otros dos sitios del Delta Inferior como El Cerrillo y Arroyo Sarandí, cuyas series osteológicas se analizaron recientemente (Ramos van Raap \& Bonomo 2016). Además en el Túmulo I del Brazo Largo fue recuperado un instrumento sobre un hueso humano (MLP-Ar-45447), lo cual agrega aún mayor variabilidad a la manipulación y tratamiento que se le dio a los restos humanos en la región (Bonomo et al. 2009).
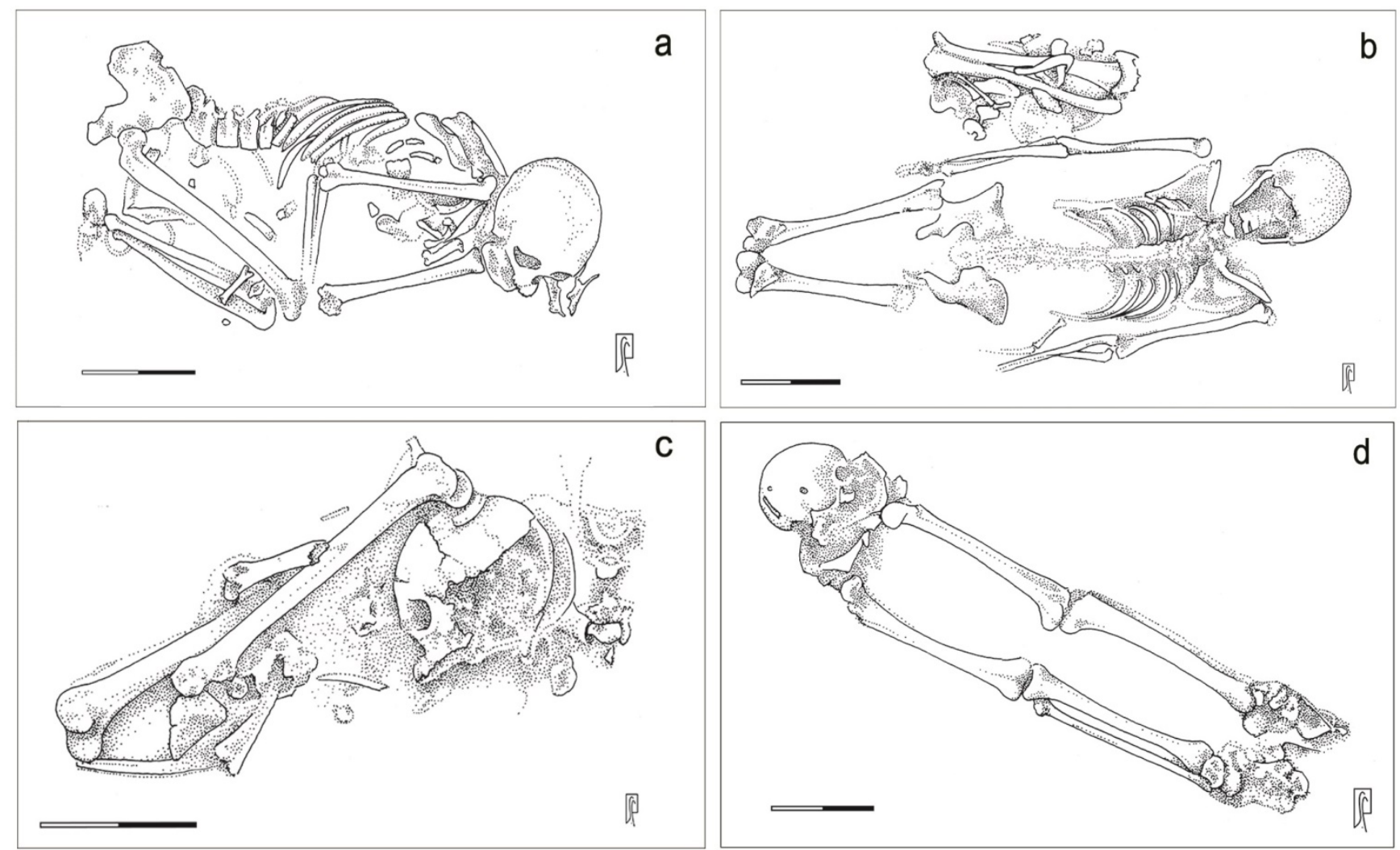

Figura 4. Entierros humanos hallados en el Delta Superior del Paraná. a. entierro primario en posición decúbito lateral izquierdo de un adulto femenino (LTC1-P4); b. entierro primario en posición decúbito ventral de un adulto mayor femenino (LTC1-P3) junto con un paquete funerario múltiple (LTC1-S2); c. paquete funerario múltiple (LTC1-S1) y d. entierro con ausencia de huesos y reubicación del cráneo (LDLG2-1).

Tal como fue observado en LTC1, un aspecto interesante y compartido entre varios de los sitios es la depositación de algunos entierros sobre capas de valvas y tiestos cerámicos, o cubiertos por ellos (p. ej. sitios Isla del Indio y Arroyo Arenal; Ceruti 1981; Pérez Jimeno 2007). Otros ejemplos incluyen los contenedores cerámicos asociados con los entierros de los sitios El Capón 2 (Cocco et al. 2004) y Río Salado Coronda II (Feuillet Terzaghi 2009) y los fragmentos de vasos cerámicos hallados cerca de uno de los esqueletos en el Cementerio de Mazaruca (Outes 1912). Por otro lado, algunos individuos fueron inhumados junto con objetos de diversa ergología. Tal es el caso de un entierro del Paradero-Cementerio Brazo Largo que se halló con un 
cráneo de aguará guazú (recientemente corroborada su determinación taxonómica a partir del análisis del ejemplar), alisadores de cerámica, una mano de mortero y un pulidor (Gatto 1939). También para El Cerrillo se hace referencia a un entierro primario acompañado con varios instrumentos óseos (Ramos van Raap \& Bonomo 2016) y en el sitio Anahí se encontró un entierro primario junto con gran cantidad de cerámica decorada, material lítico, cuentas malacológicas, material de hueso y asta (Lafon 1971). El caso más distintivo procede del sitio La Palmera II, donde se halló un paquete funerario cubierto por bloques de arenisca y tosca y asociado con instrumentos de hueso, cuentas de collar, apéndices ornito y antropomorfos, una plaqueta de cobre perforada y con otros elementos óseos humanos (Ceruti 2018). Los huesos y dientes humanos asociados con el entierro fueron interpretados como posibles sacrificios humanos (Ceruti 1993). Otro paquete funerario de este mismo sitio estaba circunscripto por concreciones de tosca y había tiestos rodeando los huesos y entre ellos; y en el centro del fardo, dos lascas (Ottalagano et al. 2015). Además de la delimitación de estos entierros mediante concreciones de tosca, las inhumaciones se caracterizan por una mayor diversidad de objetos, que indicarían un estatus diferencial de los individuos allí inhumados. Los objetos de metal hallados junto a individuos enterrados en sitios del Delta Inferior (Túmulo I y II del Paraná Guazú y Túmulo I del Brazo Gutiérrez), también fueron interpretados como posibles marcadores de diferencias sociales dentro de los grupos (Bonomo et al. 2017b, p. 10). Finalmente, se ha descripto la asociación de restos faunísticos en algunas inhumaciones de los sitios Isla Talavera, Don Santiago y La Argentina (Caggiano 1984; Caggiano \& Flores 2001; Acosta \& Mazza 2016). Un caso excepcional es el del Túmulo II de Brazo Largo en donde se encontraron asociados con uno de los cráneos humanos restos de carnívoros (cráneos, premaxilar y otros fragmentos craneales) correspondientes a Oncifelis geoffroyi, Chrysocyon brachyurus, Herpailurus yagouarundi y Lontra longicaudis (Politis et al. 2017; Figura 5). Los hallazgos de cráneos de cánidos y/o félidos junto a entierros humanos, no sólo en estas áreas sino también en la región pampeana, han sido interpretados como el producto de conductas rituales, ya que estos animales podrían haber sido referentes simbólicos o haber tenido un lugar especial en la esfera ideacional de las poblaciones (Bonomo 2006). Particularmente en el Delta Inferior, se propuso que estas asociaciones podrían indicar un "vínculo especial con la persona inhumada" (Acosta \& Mazza 2016, pp. 197-198).

Figura 5. Cráneos de carnívoros asociados a un cráneo humano ( $\mathrm{n}^{\circ}$ 6131) del Túmulo II de Brazo Largo. a. Lontra longicaudis (lobito de río, MLP-Ar-22.771); b. Oncifelis geoffroyi (gato montés, MLP-Ar-22.770) y c. Herpailurus yagouaroundi (yaguarundí, MLP-Ar-22.769).

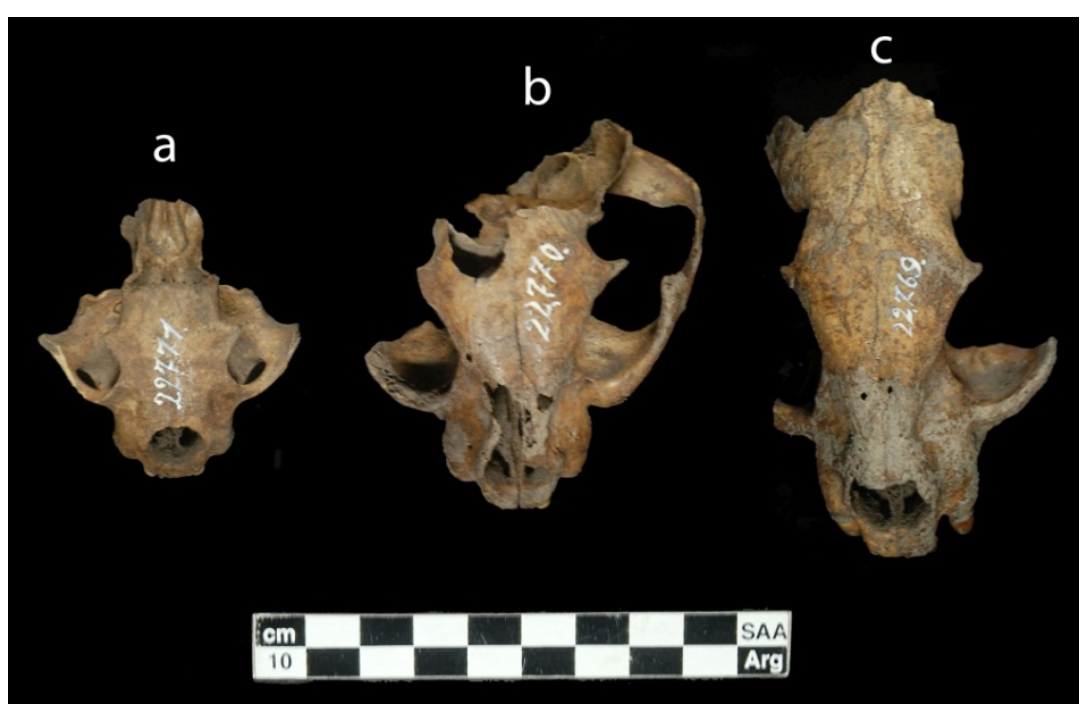

$\mathrm{Al}$ analizar en conjunto los datos disponibles sobre las prácticas mortuorias relevadas en diversos sitios del NEA, fueron observadas ciertas distinciones en los sitios asociados con la entidad arqueológica Goya-Malabrigo con respecto a las modalidades de entierro (Ramos van Raap 2018b). Por un lado, para los entierros humanos de esta entidad se registra una mayor cantidad de individuos a los que se les ha aplicado pigmento rojo, sin discriminar por sexo, edad y/o tipo de entierro. La otra diferencia son los huesos humanos en contextos de termoalteración en sitios Goya-Malabrigo del Delta Superior (LTC1; Cerro Grande del Paraná Pavón, González 1947; Cerro Grande de la Isla de Marinos, Gaspary 1950). Asimismo, se destaca la posible distinción de las inhumaciones de algunos individuos, como los hallados en La Palmera II. Todos estos aspectos mencionados 
para entierros Goya-Malabrigo, si bien no deben considerarse como exclusivos de esta entidad, se expresan de manera más notoria (Ramos van Raap 2018b).

\section{Tecnología cerámica}

La alfarería del curso medio e inferior del río Paraná se encuentra generalmente fragmentada y en grandes cantidades, por lo general superiores a los miles de ítems por sitio. Los conjuntos están integrados por fragmentos de asas, bases, cuerpos, cuellos y bordes de contenedores que poseen diferentes tamaños y formas (ollas, escudillas, cuencos, cucharas, pavas, entre otras; véase Silva 2018). También se elaboraron objetos que no corresponden a recipientes, sino que estuvieron involucrados en otras prácticas, como el adorno (pendientes y cuentas circulares y bicónicas), la pesca (pesas de red) y el hilado de fibras (torteros). En este diverso repertorio de piezas se destacan los modelados zoomorfos, que integran vasijas (aunque generalmente aparecen separados de los contenedores) y campanas (piezas acampanadas o tronco-cónicas con una abertura basal, uno o más orificios en la parte superior o lateral y uno o dos modelados macizos zoomorfos; Gaspary 1945). En muy baja proporción, se han hallado vasijas enteras, que representan valiosos materiales de referencia (Iribarne 1937; Badano 1940; Gaspary 1950; Serrano 1950; Caggiano 1984; Ceruti 2003; Ottalagano 2009, 2013; Bonomo et al. 2011a; Bonomo 2012; Barboza \& Píccoli 2013; Píccoli 2014; Di Prado 2015, 2016, 2018; Letieri et al. 2015; Sartori 2015a; Silva 2018). El estudio sistemático de piezas halladas enteras o reconstruidas, atribuidas a GoyaMalabrigo, permitió definir categorías morfológicas que dan cuenta de la variedad de formas cerámicas presentes en esta entidad. Se identificaron vasijas abiertas de contorno simple como vasos, cuencos y escudillas, así como cucharas, que se definen como cuencos y escudillas pequeñas de forma elipsoidal con un tubo o vertedera lateral. Las vasijas cerradas de contornos simples o compuestos incluyen ollas, tinajas, botellas y pavas. Estas últimas son una variante de la morfología de las ollas, de forma elipsoidal, con cuello, un apéndice tubular y otro zoomorfo (Silva 2018; Figura 6).

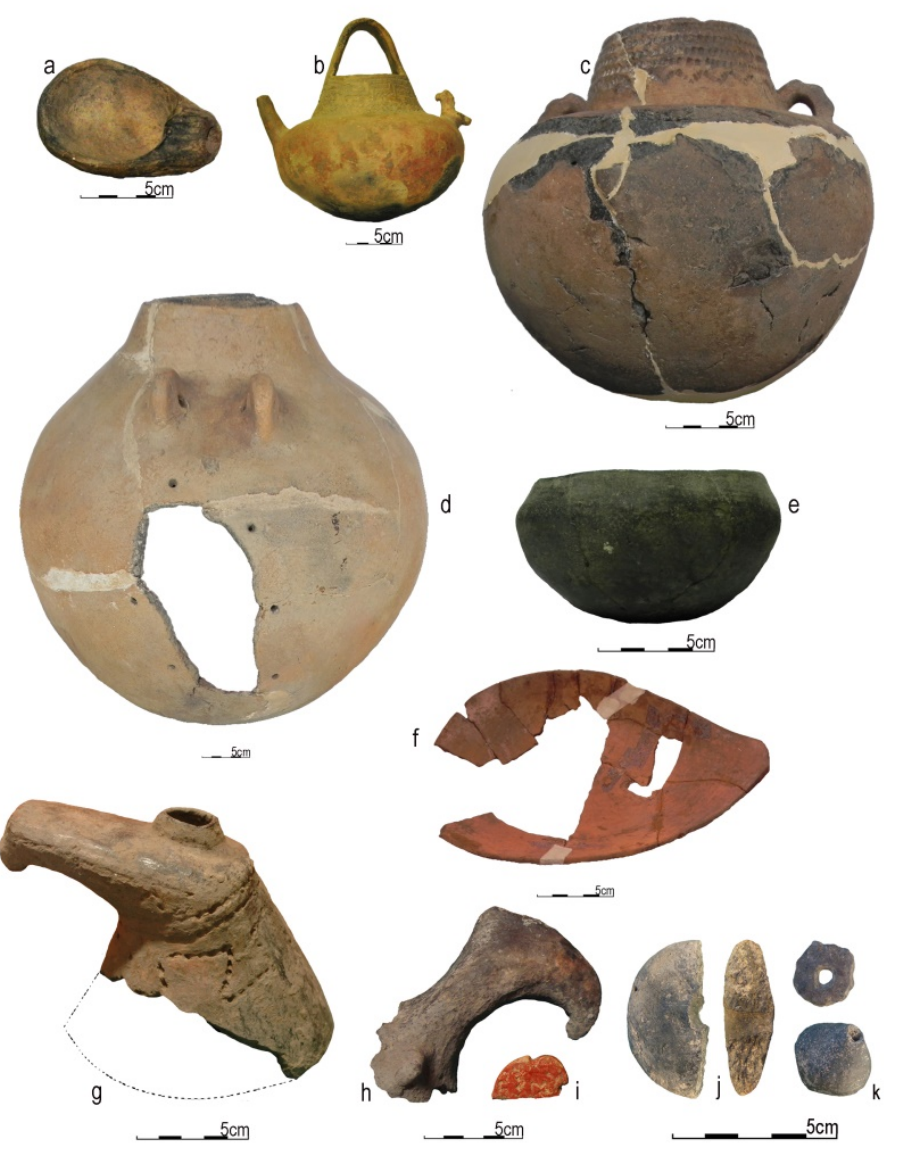

Figura 6. Diversidad tecno-morfo-estilística de la cerámica Goya-Malabrigo. a. cuchara proveniente de la Isla del Pillo y b. "pava" hallada en el sitio Los Laureles (colección particular de Roberto Oberti, Victoria); c. tinaja proveniente de Hernandarias (colección del Museo de Ciencias Naturales y Antropológicas "Profesor Antonio Serrano" de Paraná MCNAP-); d. botella recuperada en Arroyo Arenal IV (MCNAP); e. cuenco recuperado en Los Laureles (colección particular de Roberto Oberti, Victoria); f. escudilla procedente de San José de Rincón (Museo Etnográfico y Colonial "Juan de Garay" de Santa Fé); g. campana; h. apéndice zoomorfo tridimensional e i. bidimensional, j. tortero y k. cuentas de collar, todos hallados en la localidad arqueológica Los Tres Cerros. 
La ubicuidad, buena preservación y diversidad formal de la cerámica del Paraná Medio e Inferior permiten abordar diferentes aspectos de los grupos prehispánicos del área. A pesar de su relevancia para la arqueología regional, su estudio ha estado enfocado hasta hace unos años en sus atributos más sobresalientes (decoración y morfología), con un marcado énfasis en la elaboración de tipologías. Como ya fue mencionado en los antecedentes, los análisis ceramológicos realizados hasta la década de 1970 incluyeron detalladas descripciones formales y estilísticas, sobre cuyas variaciones regionales se construyeron las secuencias de desarrollo cultural (Ambrosetti 1894; Torres 1903, 1911; Outes 1918a; Aparicio 1936; Serrano 1972; Gaspary 1950). Complementariamente, la información etnohistórica fue utilizada para correlacionar la variabilidad de la cultura material con etnias históricas como los chaná-timbú o los guaraníes (véase discusión en Howard \& Willey 1948; Ceruti 1986). Entre 1970 y fines de 1990, se complejizaron los planteos en torno a las entidades culturales, se incorporaron métodos de excavación y análisis sistemáticos y se realizaron descripciones más completas de la alfarería. Sin embargo, el propósito de ordenar el registro cerámico en modalidades culturales perduró durante este período (Lafon 1971; Schmitz et al. 1972; Caggiano 1984; Ceruti 1986, 1992, 2003; Rodríguez 2001).

En las últimas dos décadas, se han comenzado a abordar temas poco explorados de los conjuntos cerámicos, en ocasiones mediante la aplicación de técnicas arqueométricas. Se han profundizado diversos aspectos del proceso de manufactura a partir de la combinación de estudios experimentales, tecnomorfológicos y microscópicos, y se ha analizado la decoración desde diferentes perspectivas. También se están explorando el uso de la alfarería, a partir de la arqueología experimental, del análisis químico y de microrrestos vegetales en residuos orgánicos, y las alteraciones postdepositacionales (Ceruti \& Traver Borny 2007; Feuillet Terzaghi \& Escudero 2006; Loponte 2008; Ottalagano 2009, 2013; Pérez et al. 2009, 2015; Capdepont \& Bonomo 20102011; Coll \& Katalinich 2010; Bonomo et al. 2012; Barboza \& Píccoli 2013; Píccoli 2014; Di Prado 2015, 2016; Píccoli \& Barboza 2016; Castro 2017; Silva 2017).

En el Delta Superior los programas metodológicos mencionados en el párrafo anterior se están aplicando para conocer las prácticas de elaboración, circulación y uso de la alfarería y los procesos postdepositacionales que afectaron su preservación. Los conjuntos analizados hasta el momento fueron recuperados tanto en sitios en posición superficial (Los Laureles -LL-, Cerro Barrancas -CB, Cerro El Durazno -CED-, Figura 2) como estratigráfica (Cerro Los Cardos -CLC- y LTC1, CTV, LDLG1 y 2 y CF, Figura 2) (Bonomo et al. 2011b, 2014, 2016; Di Prado \& Castro 2014; Di Prado 2015, 2016; Castro 2017; Silva 2017). En la mayoría de los sitios se infirió la producción in situ, en base a la presencia de desechos de manufactura (rollos, masas de arcilla con huellas de amasado y cocción parcial; Figura 6). En LTC1 se registraron, además, posibles herramientas (alisador) y recursos minerales utilizados en la terminación de las superficies (capa de sedimentos con pigmento rojo en estratigrafía). La producción local también se ha propuesto para otros sitios del área como Cerro Puesto Acosta (Ottalagano 2013, p. 63).

Las materias primas arcillosas utilizadas son expuestas por la acción fluvial y se encuentran disponibles en las inmediaciones de los sitios. Presentan inclusiones no plásticas naturales de cuarzo monocristalino, óxidos de hierro, feldespatos y micas, con tamaños predominantes correspondientes a limo grueso-arena muy fina. En los distintos sectores del Paraná, además de utilizar arcillas fluviales, se compartía la práctica de agregar tiesto molido como antiplástico para elaborar las pastas de piezas con diversos atributos tecnomorfoestilísticos y funciones (Capdepont \& Bonomo 2010-2011; Ottalagano 2013; Ottalagano \& Pérez 2013; Píccoli 2014; Letieri et al. 2015; Di Prado 2016). Los tiestos molidos se presentan subangulosos a angulosos, exhiben heterogeneidad granulométrica (con tamaños comprendidos entre arena fina y sábulo) y poseen colores que varían entre castaño rojizo, rojo tenue y rojo oscuro; algunas inclusiones de tiesto molido están atemperadas a su vez con otro tiesto molido. La adición intencional de este tipo de inclusión pudo estar condicionada tanto por factores técnicos como sociales y simbólicos (Di Prado 2016). Asimismo, en la alfarería de LTC1 se identificaron procedimientos particulares en la etapa de preparación de las mezclas arcillosas para elaborar las campanas (inclusiones no plásticas en porcentajes inferiores al 20\%) y algunas vasijas asociadas con los entierros humanos (mayor trabajo de amasado evidenciado por porcentajes de cavidades inferiores al 10\%). 
En relación con las etapas intermedias del proceso de manufactura se utilizó la técnica de superposición de rollos de arcilla para elaborar los sectores del cuerpo superior y el borde de los contenedores; las costuras entre los rodetes han sido obliteradas por la aplicación de posteriores tratamientos de superficie, tales como alisado, pulido y aplicación de pigmento rojo. Estos últimos sí dejaron huellas, como rayas y surcos poco profundos dispuestos en forma paralela y entrecruzada. Se destaca el hallazgo de tiestos y masas de arcilla con improntas de redes o cestos (Serrano 1922; Ceruti 1984; Gianotti \& Bonomo 2013) que, junto con los torteros, evidencian el tejido de fibras que no se han preservado en el registro. Las variantes del inciso, sobre todo el surco rítmico y el inciso de línea llena, fueron aplicadas para plasmar unidades de diseño no figurativas tales como líneas rectas, en zigzag y almenadas; en algunos casos estos elementos decorativos se elaboraron mediante pastillaje y pigmento rojo. Por su parte, los apéndices fueron confeccionados mediante modelado y el pastillaje y el inciso fueron utilizados para representar ciertos rasgos (ojos, boca, narinas, plumas, manchas de la piel, vibrisas, placas dérmicas; Figura 6). Los referentes figurativos plasmados en los apéndices incluyen mamíferos, moluscos, reptiles y aves; estas últimas predominan tanto en los conjuntos del Paraná Medio como Inferior. En menor medida también se encuentran representaciones antropomorfas que muestran posibles peinados, el uso de tocados, vinchas y tatuajes o pinturas faciales y perforaciones en los lóbulos de las orejas. En LTC1 se reconocieron hasta el momento cinco campanas en estratigrafia de las cuales dos se hallaron casi completas (Figura 6). Ambas presentan el cuerpo de forma troncocónica y una posee un apéndice que representa la cabeza de un ave y trazos rectos y en zigzag, efectuados mediante inciso de surco rítmico.

En el Delta Superior se confeccionaron principalmente apéndices recortados (figuras bidimensionales o siluetas) y macizos (figuras tridimensionales macizas) y hasta el momento no se han identificado motivos zoomorfos elaborados completamente con la técnica de incisión (Ceruti 1984, p. 86; figuras bidimensionales incisas, sensu Ottalagano 2009, p. 185) que sí se han reconocido en cerámicas del Paraná Medio (Ceruti 2003; Ottalagano 2009, p. 194). Los tipos de representaciones plásticas reconocidos en los sitios CB, LTC1, CTV y LDLG apoyan las variaciones espaciales identificadas por Serrano (1972; véase también las observaciones de Aparicio 1936 y Lafon 1972), quien sostiene que hacia el sur de la distribución de Goya-Malabrigo predominan los apéndices macizos y recortados. Las campanas halladas en LTC1 poseen el cuerpo "acampanado" y no se registraron cuerpos "cilindriformes", que sí están presentes en el Paraná Medio (Serrano 1972). Esto mismo fue observado en el Cerro Grande de la Isla de Marinos por Gaspary (1950, p. 39). El autor describió solo formas acampanadas y puntualizó que en sitios ubicados más al norte predominan los cuerpos cilíndricos. A medida que se avance en el análisis de los conjuntos, estas diferencias serán reevaluadas para identificar manifestaciones materiales de los grupos o "parcialidades" que habitaban distintos sectores del Paraná (Serrano 1972; Ceruti 2003; Politis \& Bonomo 2012, p. 14, 2018b).

Para la etapa de quema se infirieron condiciones variables de cocción, que podrían ser el resultado de las posiciones que ocuparon las vasijas dentro de una estructura de cocción a cielo abierto (mayoritariamente atmósferas de cocción oxidante completa e incompleta) (Di Prado 2015). Estudios de difracción de rayos X, análisis termogravimétrico y térmico diferencial (TG-ATD) y dilatometría aplicados sobre cerámicas de LTC1 permitieron inferir los rangos de temperatura alcanzados durante la quema: entre $550^{\circ} \mathrm{C} \mathrm{y} 800^{\circ} \mathrm{C}$ (aunque se reconocieron piezas cocidas a temperaturas inferiores y superiores). Por otra parte, mediante análisis de macrorrestos vegetales carbonizados se identificaron carbones correspondientes mayoritariamente a espinillo, algarrobo (Prosopis) y canelón (Myrsine), árboles con maderas que poseen un poder calórico alto y duradero por lo que son muy adecuadas como combustible (Brea et al. 2013, p. 356).

Algunas piezas tienen huellas producidas por uso, particularmente restos de hollín en superficies externas y depósitos carbonosos en las internas (Figura 7). El análisis de adherencias macroscópicas en las caras internas de los contenedores permitió identificar microrrestos botánicos (silíceos y almidonosos) y ácidos grasos. Entre los microfósiles biosilíceos se observaron fitolitos de afinidad graminoide con materia orgánica adherida y espículas de espongiarios fragmentadas, que en algunos casos podrían vincularse con la portación de líquido. En cuanto a los almidones se destaca el registro de granos correspondientes a Zea mays, Phaseolus sp. y Prosopis cf. nigra (Bonomo et al. 2012, 2017a; Colobig et al. 2015). Los recipientes cerámicos fueron utilizados en 
actividades domésticas como la cocción mediante el hervido, el servicio, el almacenaje y el transporte de alimentos y líquidos y el consumo de vegetales silvestres y domesticados.

Una vez descartadas, las piezas cerámicas estuvieron sujetas a la acción de agentes y procesos postdepositacionales. El deterioro del material se refleja en su alto grado de fragmentación y las huellas de alteración: abrasión, grietas, manchas, redondeamiento, entre otras. Este deterioro está condicionado por sus propiedades tecnológicas (p. ej., tratamiento de superficie, temperatura y tiempo de cocción, porosidad), el contexto de enterramiento y el accionar de agentes naturales y culturales posteriores. El estudio de los procesos de formación de sitios en los ambientes fluviales del Paraná ha demostrado que la alteración de la cerámica está vinculada principalmente a la incidencia de las inundaciones periódicas y a las actividades agropecuarias actuales (Píccoli 2014; Silva 2017; Galligani et al. 2018).
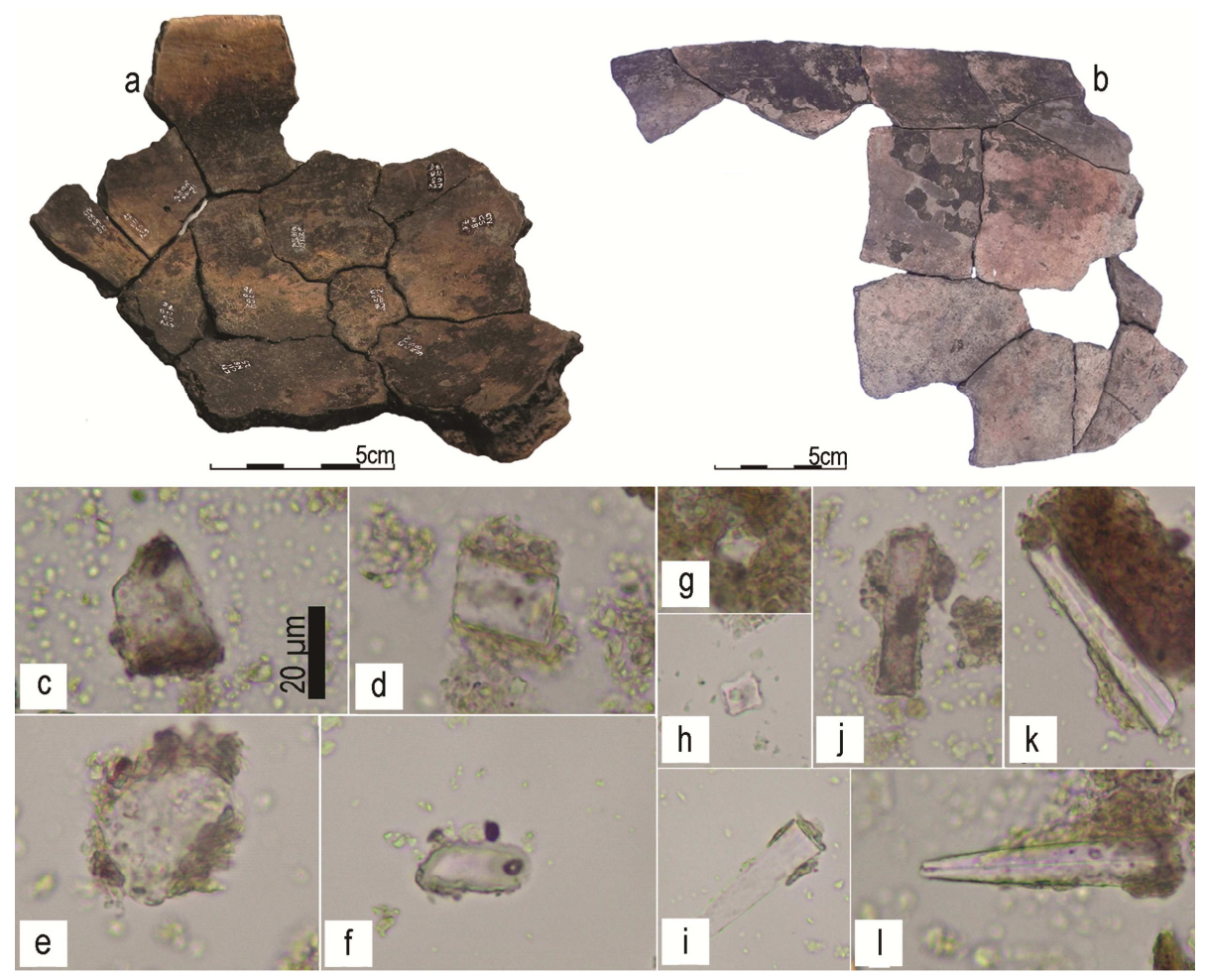

Figura 7. Frangmentos de vasijas remontadas con alteraciones por uso recuperadas en el sitio Cerro Tapera Vázquez y microfósiles biosilíceos observados en adherencias internas de tiestos hallados en el sitio Laguna de los Gansos 1. a. Restos de hollín en la superficie interna y b. externa de contenedores abiertos; c-e. microfósiles biosilíceos poliédricos; f. festoneado; g-h. cuadrados; i-j. conos truncados; cj. elementos fitolíticos de afinidad graminoide; $\mathbf{k}-\mathbf{l}$. espículas de espongiarios. Modificado de Colobig et al. (2014).

\section{Economía y organización social}

Las investigaciones recientes en el Delta Superior permitieron plantear que el área fue ocupada por poblaciones asociadas con Goya-Malabrigo, cuya subsistencia coincide a grandes rasgos con la propuesta para el Paraná Medio e Inferior (Ceruti 1981, 1992; Cornero et al. 2007; Pérez Jimeno 2007; Barboza 2014; Sartori \& Galligani 2014; Sartori 2015a). La alimentación en el área de estudio estuvo basada en la explotación de una amplia gama de recursos por medio de la caza de mamíferos (coipo -Myocastor coypus-, carpincho -Hydrochaeris hydrochaeris-, cuis -Cavia sp.- y cérvidos -Blastocerus dichotomus, Ozotoceros bezoarticus y Mazama sp.) y la pesca principalmente de Characiformes (Hoplias sp., Prochilodus lineatus, Leporinus obtusidens, Salminus brasiliensis, Piaractus mesopotamicus, entre otros) y de Siluriformes (Pimelodus maculatus, P. albicans, Rhamdia quelen, Pterodoras granulosus), y, en menor medida, el aprovechamiento de aves, reptiles y moluscos de agua dulce (Bastourre 2014, 2018; Bonomo et al. 2014, 2016; véase también González 1947 para el Cerro Grande del Paraná Pavón). Esta dieta era complementada con la recolección de plantas como algarrobo, achira y arroz silvestre y el cultivo de la difundida tríada americana de maíz-porotoszapallo. Los resultados de las investigaciones en microrrestos biosilíceos y granos de almidón han permitido constatar la presencia de recursos vegetales silvestres y domesticados en los sedimentos de los cerritos y 
también en artefactos cerámicos que los almacenaron (Bonomo et al. 2011c; Sánchez et al. 2013; Colobig et al. 2015, 2018; Colobig \& Ottalagano 2016). En un estudio reciente de isótopos estables $\left(\delta^{13} \mathrm{C}\right.$ en colágeno y apatita y $\delta^{15} \mathrm{~N}$ en colágeno) realizado sobre 22 muestras de restos óseos humanos provenientes de 15 sitios arqueológicos del Delta del Paraná y su llanura adyacente (Bonomo et al. 2017a), se observó que la mayoría de los individuos Goya-Malabrigo presentan valores isotópicos que muestran un consumo predominante de recursos $\mathrm{C}_{3}$, esto incluye vegetales domesticados o silvestres y herbívoros terrestres consumidores de este tipo de plantas. Para la captura y el procesamiento de los recursos se transformaron los huesos y las astas de los animales cazados en puntas acanaladas, semi-acanaladas y planas con y sin pedúnculo y cabezales de arpón (González 1947; Gaspary 1950; Politis et al. 2011; Figura 8). Además se utilizaron tanto para cortar como para moler escasos artefactos líticos elaborados sobre diversas materias primas -limolitas, areniscas carbonáticas y silicificadas, xilópalos, calizas silicificadas, basaltos vesiculares, cuarcitas, granitoides y calcedoniaprocedentes de las formaciones Paraná, Ituzaingó, Puerto Yeruá, Serra Geral y Botucatú, del Complejo Martín García y de los depósitos de rodados del río Uruguay (Bonomo \& Blasi 2010; Apolinaire 2017).

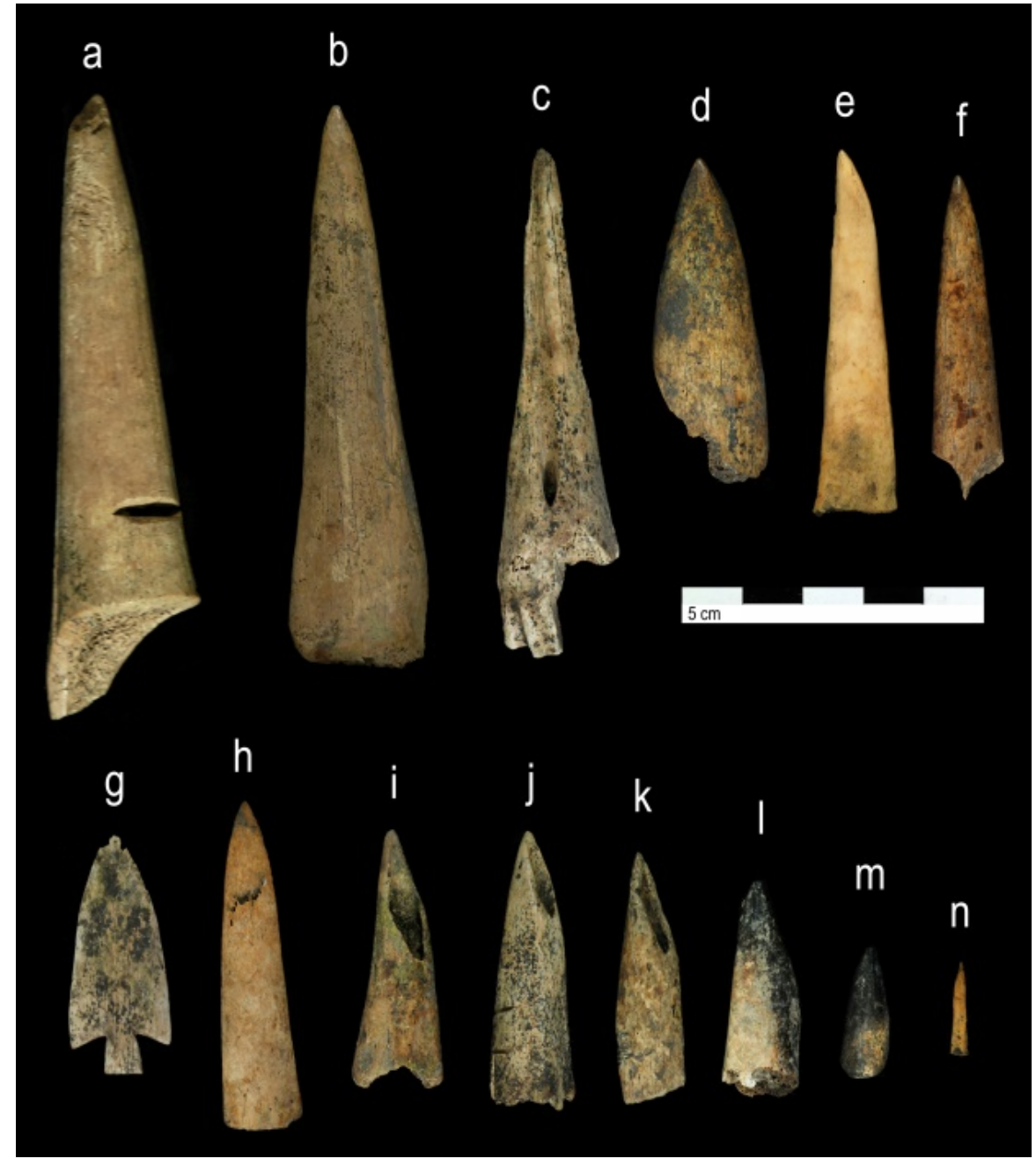

Figura 8. Instrumentos óseos recuperados durante las excavaciones del sitio arqueológico Los Tres Cerros 1. a. punta cónica (cabezal de arpón); b-f, m. puntas acanaladas; $\mathbf{g}-\mathbf{h}$. puntas planas; $\mathbf{i}-\mathbf{l}$, n. puntas semi-acanaladas.

La primera expedición europea que se internó en el río Paraná, la de Sebastián Caboto (1526-1530), describió las poblaciones carcarais, chanaes, beguas, chanaes-timbus y timbus que vivían en los alrededores del Fuerte Sancti Spíritus (1527-1529), que es el primer asentamiento español en territorio argentino y estaba localizado en frente a las islas del Delta Superior. Los nombres de estas y otras comunidades indígenas emparentadas han quedado inscriptos en la toponimia histórica y contemporánea del área: isla Chaná, río y laguna Coronda, río Colastiné, río de los Quiloazas (actual río San Javier) y río de los Chanás (posiblemente actual arroyo del Monje) (Zapata Gollan 1945). Estas poblaciones se agrupan dentro del complejo étnico chaná- 
timbú del Paraná y serían la continuidad etnográfica de Goya-Malabrigo. En otras palabras, esto quiere decir que esta entidad arqueológica muestra la profundidad temporal del "presente etnográfico" reflejado en las crónicas. Según los tempranos relatos del siglo XVI (p. ej. Ramírez [1528] en Madero 1902; Fernández de Oviedo y Valdés [1546-1547] 1851-1855; Schmidel [1567] 2009), estos indígenas tenían gran estatura y usaban vestimenta de cuero o algodón y adornos labiales y orejeras. Vivían en las márgenes ribereñas en "pueblos" con plazas donde construían grandes chozas con palos y esteras de paja tejida. Es probable también que tuvieran grandes viviendas comunales (Politis \& Bonomo 2018b). Durante las inundaciones trasladaban sus asentamientos desde las islas a las llanuras de tierra firme. Poseían cientos de canoas monóxilas de gran tamaño (80 pies de eslora con capacidad para 16 personas; Schmidel [1567] 2009, pp. 100-101) para las tareas de subsistencia, el transporte, el desplazamiento y la guerra en este medio fluvial. Explotaban sistemáticamente peces, aves, roedores de gran porte, como el carpincho y el coipo, y cérvidos en territorios de caza y pesca establecidos y con una tecnología diseñada para ello como redes, lanzas, garrotes, propulsores, arcos y flechas emplumadas (Fernández de Oviedo y Valdés [1546-1547] 1851-1855). También recolectaban miel, comían perros cebados, secaban pescados al sol y los ahumaban en parrillas de palos y obtenían de ellos "aceite" o "manteca" para su almacenamiento y consumo diferido. El documento del cosmógrafo Alonso de Santa Cruz (Wieser 1908, pp. 56-57), que participó en la expedición de Caboto, ilustra la siembra del maíz en las islas durante el verano. La famosa carta de Luis Ramírez de 1528 (en Madero 1902), también muestra que otras poblaciones además de los guaraníes, practicaban la horticultura de maíz, zapallo y poroto (véase revisión reciente en Sartori 2015b; Balducci et al. 2016; Apolinaire 2017).

La información disponible en las crónicas del siglo XVI (p. ej. Fernández de Oviedo y Valdés [1546-1547] 1851-1855; Schmidel [1567] 2009) y, en menor medida, en el registro arqueológico (véase discusión en Bonomo et al. 2011a) para el curso medio e inferior del Paraná, sugiere algún nivel de jerarquías sociopolíticas estables, evidenciadas en, al menos, un primer orden de liderazgo comunitario. Existían líderes que tenían cierto control sobre la distribución de los excedentes del producto colectivo, generados por el cultivo de maíz y la pesca. Estos excedentes superaban las propias necesidades de subsistencia de los indígenas y fueron compartidos e intercambiados con los primeros conquistadores. Los chaná-timbú también poseían cautivos guaraníes que intercambiaron con los europeos. Las evidencias arqueológicas muestran que en las tumbas de algunos individuos fueron colocados pendientes y cuentas elaborados en cobre puro y bronce al estaño (Bonomo et al. 2017b). Además de las materias primas alóctonas, las técnicas metalúrgicas de fundición, colada en moldes abiertos y laminado en caliente y los diseños repujados de estos adornos mostrarían su procedencia andina. En la mayor parte de las Tierras Bajas sudamericanas los indígenas no fabricaron objetos de metal, sino que los obtuvieron por intercambio con las poblaciones mineras de los Andes u otras intermediarias (Steward, 1944-1949). Estos bienes se trasladaron por enormes distancias por rutas indígenas prehispánicas hasta arribar al Paraná. Los metales en forma de láminas y objetos terminados (cofias, cuentas, broches, hachas) llegaban por tres rutas indígenas potenciales: la del río Carcarañá a través de las sierras de Córdoba y la de los ríos SaladoDulce a través de las llanuras de Santiago del Estero, utilizadas ambas por los chaná-timbú, y la del corredor Paraná-Paraguay a través del Chaco, seguida por los guaraníes (Bonomo et al. 2017b).

Los objetos de metal trasladados desde sus fuentes y talleres de producción, se utilizaron para marcar diferencias sociales y de rango al interior de los grupos. El trato diferencial de las personas que cuando morían se enterraban con ellos podría estar reflejando relaciones sociales asimétricas, en las que algunos miembros de la sociedad tenían un acceso desigual a bienes importados. A través del control del intercambio de productos de áreas geográficas distantes que trascendía las fronteras étnicas, estos individuos tenían la capacidad de acceder a bienes sofisticados (manufacturas en metal) que podían utilizar para consolidar su posición social, prestigio y liderazgo. Esto es apoyado por las primeras crónicas que identifican con nombres propios por lo menos a tres grandes jefes indígenas del Paraná, para los cuales empleaban las palabras "cacique principal", "señor principal" o "mayoral" en referencia a sus capacidades de gobierno y mando (Covarrubias Horozco [1611] 2006; véase también Politis \& Bonomo 2018a, pp. 23-24). Algunas islas del Paraná llevaban el nombre de estos mayorales (Wieser 1908, p. 57). En el reparto de tierras de Juan de Garay de fines del siglo XVI y en las encomiendas de 
indios de principios del XVII también se menciona una docena de nombres propios de la nación chaná (Sempé et al. 1999), parte de los cuales hacían referencia a caciques (Canals Frau 1940). Esto llevaría a proponer que los grupos indígenas no-guaraníes del Paraná (que genéricamente llamamos chaná-timbú y sus antecesores de los siglos previos al XVI), tuvieron una organización socio-política que podría incluirse dentro de lo que clásicamente se ha denominado rank society (Fried 1967; Bonomo et al. 2011a).

\section{La expansión guaraní}

Al momento de la conquista las poblaciones de la familia lingüística Tupí-Guaraní se extendían de forma continua por el litoral atlántico brasileño, ocupaban distintos tramos de la cuenca del Amazonas hasta el Chaco oriental y del pie de los Andes, así como en grandes superficies de la cuenca del Plata. Dentro de esta familia, los hablantes del Guaraní Antiguo se encontraban en una pequeña porción de la costa atlántica al sur de Paranaguá, en el Brasil meridional, Uruguay y alrededor del Río de la Plata. Hacia el interior, habitaban las llanuras aluviales de algunos cursos que desembocan en el mar y amplias áreas de las cuencas de los ríos Paraguay, Paraná y Uruguay. Desde luego, esta enorme distribución geográfica fue vista como un indicador de la existencia de una larga historia de continuos movimientos poblacionales, que incluso continuaron como consecuencia de la colonización europea (Métraux 1927; Brochado 1984; Noelli 1993; Bonomo et al. 2015; Iriarte et al. 2017b).

En arqueología, clásicamente se ha asociado la dispersión guaraní con la distribución de la alfarería policroma (rojo y/o negro sobre engobe blanco; Figura 9), corrugada, unguiculada y cepillada, los entierros en urna (Figura 10), las hachas de piedra pulidas, los adornos labiales (tembetás) y las manchas de terra preta formadas por la descomposición de materia orgánica sobre todo en las áreas de vivienda. Entre las vasijas guaraníes características, se encuentran las ollas yapepó y las cacerolas ñaetá para cocinar, los vasos cambuchí caguâba para beber, los platos ñaembé para servir la comida y los grandes cambuchi para contener agua y almacenar bebidas fermentadas a base de maíz (Brochado \& Monticelli, 1994). Las semejanzas en los patrones de asentamiento aldeano, las recurrencias tecno-morfológicas y estilísticas en los tratamientos de superficie, motivos decorativos, formas y funciones de las vasijas así como la homogeneidad en el tratamiento dado a los muertos han permitido la conformación de una entidad arqueológica distintiva que en general se solapa con la distribución que tenían los Guaraní hablantes hace más de cuatro siglos (Nimuendajú 1982; Urban 1992). Estos grupos vivían en grandes aldeas rodeadas con empalizadas defensivas y que estaban constituidas por un grupo de cuatro a ocho malocas (de ca. 40 a $160 \mathrm{~m}$ de largo) en torno a una plaza central, conducidas por el liderazgo político de un jefe denominado tuvichá. Basaban su economía en la horticultura (maíz, mandioca, batata, porotos, zapallo, maní y algodón). Estudios realizados recientemente por nuestro equipo en vasijas enteras guaraní han corroborado la presencia de maíz y de porotos, además de gramíneas y espículas de espongiarios en recipientes destinados al almacenamiento de bebidas. También recurrían a la pesca, la caza, la recolección y la cría de aves como patos (p. ej. Hernández, [1545] en Schmidel 2009, p. 202). De acuerdo con las propuestas de Brochado (1984), tendrían un origen amazónico y se expandieron a través del sistema fluvial de la cuenca del Plata. Si bien el interés por explicar científicamente las rutas seguidas por los guaraníes no es nuevo (véase Brochado 1984; Meggers et al. 1988), solo recientemente se realizó un estudio detallado de la distribución geográfica y temporal de los sitios arqueológicos atribuidos a los guaraníes (Bonomo et al. 2015). El propósito general de ese estudio fue evaluar los ritmos de expansión guaraní por las principales vías fluviales, a través de un extenso relevamiento de las coordenadas geográficas de los sitios y las dataciones disponibles y de análisis espaciales con herramientas SIG. Se relevaron más de 1600 sitios arqueológicos atribuidos a los guaraníes y alrededor de 250 dataciones absolutas $\left({ }^{14} \mathrm{C}\right.$ y termoluminiscencia). No estuvo entre los objetivos de ese trabajo correlacionar la expansión guaraní con los cambios climáticos pretéritos, tal como lo hicieron posteriormente Iriarte et al. (2017b) al asociar el incremento en las precipitaciones del Holoceno medio y tardío con la expansión de la selva tropical y el aumento de los sitios relevados previamente. Sin embargo, los cambios 
paleoclimáticos observados no se correlacionan con los dos pulsos de expansión identificados (véase abajo), ya que la escala cronológica, con intervalos de 500 años, empleada por estos autores no lo permite.
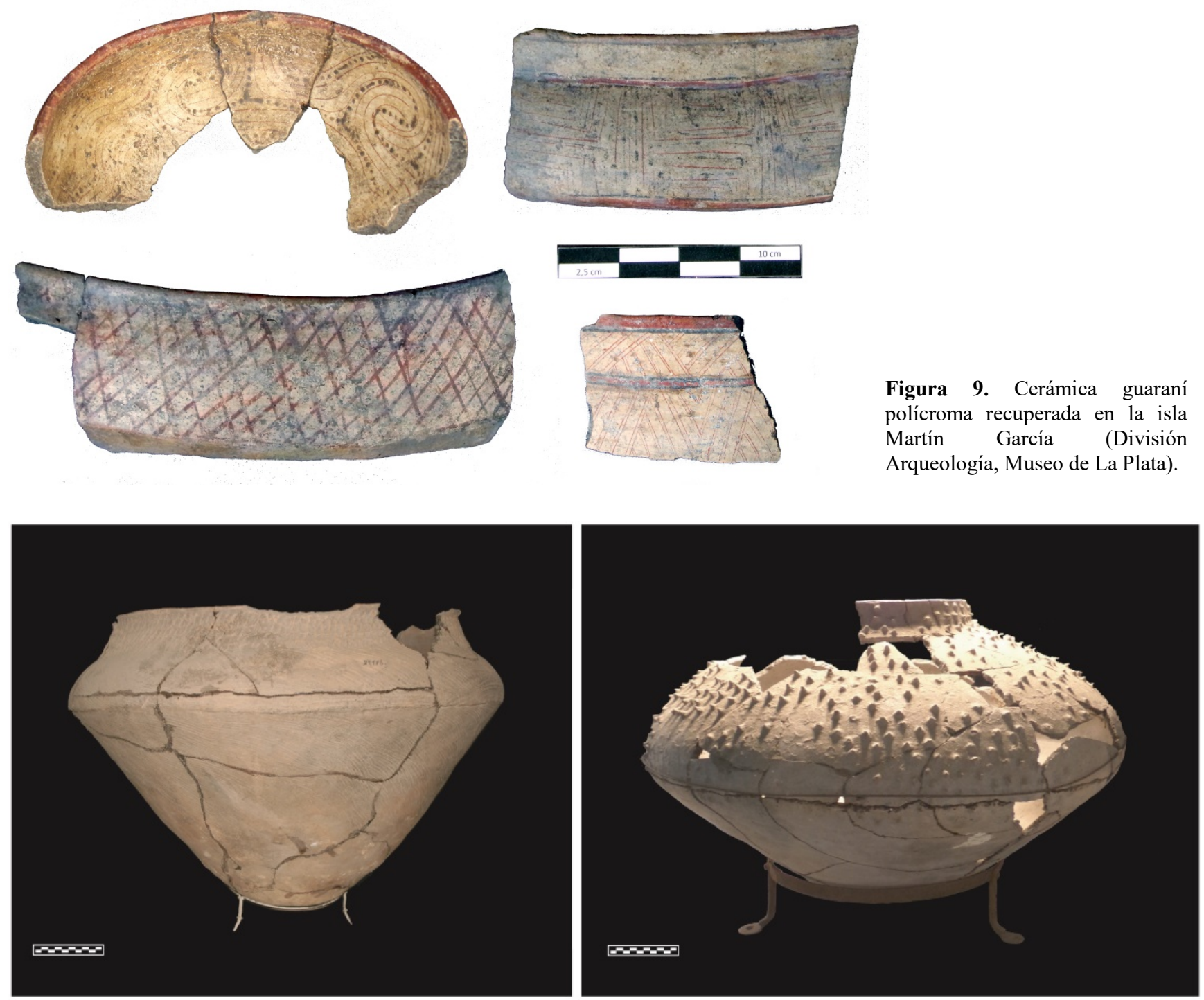

Figura 10. Urnas guaraníes recuperadas en el sitio arqueológico Arroyo Fredes por Pablo Gaggero en 1921 (MLP-Ar-24.118 y 24.149; División Arqueología, Museo de La Plata).

A partir del estudio de Bonomo et al. (2015) se observó que el sentido y el flujo de la expansión se orientaron según los cursos fluviales, lo cual seguramente también esté reflejando los patrones culturales dominantes de las poblaciones estudiadas, que al principio se desplazaban con medios de navegación y localizaban sus aldeas en los ricos ambientes fluviales de la región, rodeados de bosques y selvas. Cuando consolidaban esos territorios, pasaban a ocupar y manejar la vegetación en tramos cada vez menores de las cuencas hidrográficas hasta los inter-fluvios (Brochado 1984; Noelli 1993). Las dataciones absolutas reunidas permitieron estimar los ritmos de dispersión de estas poblaciones, que implica un mínimo de 17 siglos de historia de movimientos poblacionales y ocupación permanente de varias regiones. Durante este lapso se recorrieron miles de kilómetros, alcanzándose, hacia el sur, el Delta del Paraná y el Río de la Plata (entre los $c a$. 1340 y 1530 años AD). A partir de la construcción de un modelo de visualización temporal con una escala anual continua, mediante la utilización de las herramientas Temporal Analyst y ArcGIS 10.1, fue posible establecer dos pulsos principales de expansión. El primer pulso ocurre entre el 0 al $300 \mathrm{AD}$ que es cuando se alcanza el río Paraná, al norte de la provincia de Corrientes. Luego de un momento de estabilidad y ocupación redundante de las mismas áreas (300 al $1000 \mathrm{AD}$ ), ocurre el segundo pulso entre el $1000 \mathrm{y}$ la conquista. Este segundo pulso 
utiliza como eje el río Uruguay y continúa al sur hasta el Río de la Plata. Se registran sitios a lo largo de la selva en galería de los cursos inferiores de los ríos Uruguay y Paraná, la isla Martín García y los albardones costeros del Río de la Plata. La dinámica de movilidad dentro de este segundo pulso de expansión guaraní se altera drásticamente a partir del siglo XVI, en coincidencia con los profundos cambios producidos por la conquista y colonización europea.

Del modelo de expansión guaraní generado se desprende que el arribo de los guaraníes a las latitudes más meridionales de su distribución geográfica (el Río de la Plata y el Delta del Paraná) se efectuó siguiendo el cauce del río Uruguay, para después ocupar algunas áreas del Paraná Inferior. En la propuesta de Brochado (1984), además de la ruta del río Uruguay, también sugiere el tramo del Paraná Medio-Inferior como posible vía de acceso al Río de la Plata. Sin embargo, la información arqueológica disponible no apoya esta posibilidad y muestra que el Paraná Medio (aguas abajo de la desembocadura del río Paraguay) y el Delta Superior estaban densamente ocupados por otros grupos humanos que se asocian con Goya-Malabrigo durante el segundo pulso de expansión guaraní. El registro arqueológico de este tramo del Paraná no muestra claras ocupaciones efectivas o aldeas de los guaraníes (Rodríguez \& Ceruti 1999; Bonomo et al. 2015; Politis et al. 2018). En el Delta Superior solo se han registrado materiales aislados: un entierro en una urna polícroma, cuatro recipientes completos y un número reducido de tiestos corrugados, unguiculados y escobados. A excepción de algunas crónicas del siglo XVI (Bonomo et al. 2011a) que mencionan a los guaraníes en los alrededores del Fuerte Sancti Spíritus, los asentamientos efectivos de estas poblaciones se restringen a las islas más externas y recientes del Delta Inferior del Paraná (Outes 1918b; Lothrop 1932; Loponte 2008; Bonomo 2012, 2013; Politis et al. 2018). En la porción meridional de su distribución los materiales guaraníes aparecen muchas veces en la superficie o en las capas superiores de sitios ocupados por otros grupos, tal como se observa en el Uruguay Medio, Delta del Paraná y Río de la Plata (Cigliano et al. 1971; Ceruti \& Crowder 1973; Rodríguez \& Rodríguez 1985; Bonomo 2013). La preexistencia de otras poblaciones, sin dudas redirigió la expansión y en algunos casos impidió la ocupación efectiva de determinados territorios por los guaraníes.

En cuanto al registro bioarqueológico, este se caracteriza por ser menos abundante en comparación con Goya-Malabrigo. Las modalidades de inhumación registradas en los sitios guaraníes se corresponden con entierros secundarios en urnas y entierros primarios en tierra. En el Delta Inferior, en los sitios Arroyo Fredes, Arroyo La Glorieta y Arroyo Malo fueron recuperadas urnas funerarias con huesos de individuos subadultos y/o adultos (Gaggero 1925; Castro 1926; Lothrop 1932; Mazza et al. 2016; Ramos van Raap \& Bonomo 2016). Como característica común en estos entierros secundarios simples y múltiples, se distingue el uso generalizado de pigmento rojo para colorear los huesos. Por otro lado, una de las siete urnas halladas en Arroyo La Glorieta poseía también en su interior cuentas de collar y restos faunísticos (Castro 1926). Además de estas inhumaciones en urna, en Arroyo Malo y Arroyo Fredes se identificaron entierros humanos directos en tierra, algunos de ellos pintados de rojo, acompañados con vasijas, restos faunísticos y artefactos líticos (Gaggero 1925; Lothrop 1932; Ramos van Raap \& Bonomo 2016). Este tipo de prácticas también habría estado presente en el sitio Ensenada del Bellaco, ubicado en el área aledaña de la cuenca inferior del río Uruguay (Ramos van Raap \& Scabuzzo 2018b); y también se han reportado en sitios más distantes, en los estados de Rio Grande do Sul y Paraná (Noelli 1993; Pestana 2007; Neumann 2008).

\section{Conclusiones}

Sin duda, en el Paraná Inferior y Medio, la entidad arqueológica mejor representada y estudiada es GoyaMalabrigo. Como se ha expresado, sus rasgos fundamentales son la hidrocentralidad, un patrón de asentamiento en el que sobresalen los cerritos y una economía basada en la caza, la pesca, la recolección y una horticultura a pequeña escala. Los cultivos parecen estar presentes desde los momentos iniciales de las ocupaciones GoyaMalabrigo en la región, mostrando que no se trata de una horticultura "incipiente" adoptada tardíamente por cazadores-recolectores-pescadores en un contexto de intensificación, sino de poblaciones ribereñas que poseían 
una exitosa economía mixta que combinó actividades extractivas con la producción de alimentos de origen vegetal.

Los montículos de tierra, los "cerritos" del Paraná, son estructuras antropogénicas, producto de una importante inversión de trabajo humano que quedó inscripta de manera permanente en el paisaje fluvial por casi dos milenios. Son estructuras arquitectónicas muy difundidas en las Tierras Bajas sudamericanas que conformaban el paisaje cultural de las planicies anegadizas del curso inferior del río Paraná y que allí se asociaban con poblaciones con algún grado de diferenciación étnica, lingüística, económica y sociopolítica. La mayoría de los montículos del Paraná han sido asignados a Goya-Malabrigo aunque, sobre todo en el Delta Inferior, también han sido asociados con la facie Ibicuy o Ibicueña. Sus características y contexto sociocultural son diferentes a los de los montículos de áreas cercanas, como los del este de Uruguay y sureste del Brasil asociados con la Tradición Vieira. Aunque desligados de su génesis indígena, hoy en día los cerritos arqueológicos siguen siendo utilizados en el Paraná para la instalación de puestos ganaderos, colmenas, campamentos de pescadores y cazadores, la extracción de tierra negra para la jardinería o bien se construyen nuevos con máquinas para proteger de las inundaciones bienes muebles e inmuebles. Hay otros rasgos en tierra que también organizan la vida de los pobladores actuales y su movilidad, como son los cortes rectilíneos o canales hechos a pala en tiempos históricos para conectar cursos adyacentes y acortar distancias de navegación por largos meandros. A futuro habría que evaluar mejor la profundidad temporal de esta práctica.

Los montículos del Paraná Inferior han tenido en principio funciones residenciales y funerarias, y fueron sitios principales dentro de la jerarquía de asentamientos de la región. Es probable que los más importantes hayan sido locus de aldeas y algunos se hayan usado para la horticultura. Debido a su propiedad acumulativa, una vez que los montículos se construyeron, sus registros y evolución constructiva dan cuenta que su mantenimiento y reclamación cultural fue transgeneracional. Luego de ser elevada una superficie ocupacional, se generó un círculo virtuoso para futuros asentamientos, potenciando las ventajas estratégicas de la instalación en áreas con abundantes recursos acuáticos, debido a que se transformaban en espacios atractivos. La secuencia repetida de elevación-ocupación-descarte-abandono-elevación/acondicionamiento-reocupación creó estructuras que incrementaron su altura con el paso del tiempo. Así, se fueron transformando en lugares privilegiados del paisaje y referencias para el pasado comunitario. Esto último se refuerza con que, además, estos espacios domésticos compartieron un mismo lugar con los entierros humanos. Ello seguramente incidió en que estos espacios destinados a los ancestros se transformaran en centros de construcción, negociación y reafirmación de la memoria colectiva (véase p. ej. casos similares en Pauketat 2004, pp. 47-49 para el río Misisipi y Erickson 2009, p. 222 para los Llanos de Mojos). El hábito de enterrar a los muertos donde se vivía pudo generar fuertes vínculos identitarios entre los grupos vivos y los antepasados en puntos concretos de este paisaje socialmente construido. La gran complejidad en las conductas de tratamiento de los muertos que se plasma en el armado de paquetes funerarios, en la selección de partes, en las prácticas de descarne, aplicación de arcilla y pigmentos de potente color rojo, señala una importante inversión de tiempo en la preparación de los restos de los antepasados y muestra su papel central en la reproducción social. A estos tratamientos de los cuerpos se le debe añadir el hallazgo en los sitios del Delta Superior de restos humanos termoalterados, en muchos casos contenidos dentro de estructuras de fogón --que en el caso de Los Tres Cerros 1 se localizan en un punto destacado dentro del montículo.

La cerámica Goya-Malabrigo del Paraná no fue solo utilizada en prácticas culinarias y mortuorias, sino que también participó en diversas actividades, tales como el hilado, el adorno, la manufactura cerámica, entre otras. Una práctica recurrente es el reciclado de fragmentos cerámicos en tiesto molido, cuentas, torteros, material constructivo para elevar los cerritos y artefactos para decorar y alisar las superficies cerámicas. Mientras que algunos tiestos fueron modificados mediante acciones mecánicas (torteros, cuentas) otros se utilizaron sin modificar (tiestos posiblemente empleados para decorar nuevos recipientes). Incluso existen referencias etnohistóricas que afirman que los habitantes del Paraná hacían bollos de barro fritos en grasa de pescado, que constituían un manjar en las comidas (Lozano 1874 en Chiri 1974: 246). Todas estas prácticas se contextualizan en el marco de la intensa relación que los habitantes prehispánicos del Paraná entablaron con la arcilla, a través 
de su incorporación a la vida cotidiana, a la modificación del paisaje y al mundo simbólico (véase discusión en Politis \& Bonomo 2012; Di Prado 2015).

La homogeneidad en los modos de decorar la alfarería del Delta Superior, se ve reflejada en la aplicación de las técnicas de modelado y pastillaje para elaborar representaciones plásticas, principalmente zoomorfas, que formaban parte de campanas y vasijas con diversas formas. Las variantes del inciso, mayoritariamente el surco rítmico, fueron utilizadas para plasmar diseños no figurativos en los contenedores, pero también para representar los rasgos de los modelados figurativos. Mientras que los apéndices zoomorfos (y las campanas) son conspicuos en el registro del Nordeste de los últimos 2000 años AP (Ceruti 2003; Ottalagano 2009; Bonomo 2012; Politis \& Bonomo 2012; Píccoli 2014; Di Prado 2015), las variantes del inciso también forman parte de las tradiciones de manufactura cerámica de la Pampa Húmeda y el este de Norpatagonia (véase discusión y citas en Di Prado 2018).

Las regularidades registradas sobre todo en las formas y la decoración de la cerámica de los sectores medio y deltaico del Paraná fueron interpretadas por Ottalagano (2009) y Politis et al. (2011, p. 86) como indicadores de un estilo emblemático (sensu Wiessner 1983, pp. 257-258; véase también David et al. 1988, pp. 378-379). Es decir, que estos atributos de la alfarería contenían información acerca de la identidad social de los integrantes de un grupo o comunidad, quienes además eran conscientes de ello. El estilo emblemático genera un patrón distintivo de visibilidad arqueológica (Wiessner 1983). Como fue señalado en el párrafo anterior, esto se aplicaría para algunas técnicas (modelado) y objetos (campanas, apéndices zoomorfos), pero no para la totalidad de los recursos técnicos (variantes del inciso) ni de las representaciones decorativas no figurativas.

Las poblaciones Goya-Malabrigo de la llanura aluvial del Paraná (y del Uruguay Inferior), no solo construyeron montículos para asentarse en zona inundable, fabricaron canoas, redes, puntas y arpones para explotarlos, sino que además crearon una frontera social que limitó la instalación de los recién llegados guaraníes. A pesar de esta resistencia, algunos objetos e individuos circularon más allá de las aldeas guaraníes y permearon nuevos territorios y comunidades. El arribo posterior de los europeos al Río de la Plata, que generó el registro escrito para reconstruir el pasado de estas poblaciones, trajo consigo epidemias de enfermedades desconocidas, crueles matanzas y el reparto de indios. Esto afectó drásticamente la historia indígena regional y con ello alteró el proceso de expansión poblacional que los guaraníes habían desarrollado a lo largo de los sucesivos siglos de dispersión por vastas áreas del continente. En este proceso los guaraníes se desplazaron hacia el sur y se asentaron en la porción más joven del Delta del Paraná. No obstante, a diferencia de otros grupos indígenas, estas poblaciones lograron adecuarse a esta nueva situación colonial, a las misiones jesuíticas y aprovechar el nuevo escenario para continuar expandiendo su cultura y su lengua que hoy es hablada por seis millones de personas en América del Sur.

\section{Agradecimientos}

Este estudio fue realizado en el marco de los proyectos "Arqueología de ambientes acuáticos del centroeste argentino" (UNLP 11/N885), "Arqueología del Delta Superior del Paraná: enfoque multidisciplinario" (PIP-CONICET 0467) y "Arqueología del sector meridional del Noreste argentino" (PICT 1064) y "Aporte Interdisciplinario a la arqueología del litoral del río Uruguay, Argentina" (PICT 2723). Los autores agradecen a Diego Gobbo, Bruno Pianzola, Samanta Faiad y Germán Moreira por la ayuda brindada con las figuras. Y a los revisores que contribuyeron en la calidad del manuscrito.

\section{Referencias bibliográficas}

Acosta, A. \& Loponte, D. (2008) “Sociedades originarias. Una economía a base de caza, recolección y pesca”. En: Atlas Total Clarín de la República Argentina 12, Buenos Aires, Arte Gráfico Editorial Argentino, pp. 62-69. 
Acosta, A. \& Mazza, B. (2016) "Restos óseos humanos y faunísticos: su relación en el espacio mortuorio en contextos de cazadoresrecolectores del humedal del Paraná inferior (Argentina)”. Pesquisas, Antropología 72, pp. 185-207.

Ambrosetti, J.B. (1894) "Los paraderos precolombinos de Goya (Pcia. de Corrientes)”, Boletín del Instituto Geográfico Argentino XV(9 y 10), pp. 401-422.

Acosta A., Loponte, D. \& Tchilinguirián, P. (2013). Nuevos aportes para la arqueología del humedal del Paraná inferior. El sitio Médanos de Escobar. Relaciones de la Sociedad Argentina de Antropología 38(1), pp. 19-35.

Ameghino, F. (1881) La Antigüedad del Hombre en el Plata, T 2, Buenos Aires, Igon Hermanos.

Aparicio, F. (1928) "Notas para el estudio de la arqueología del Sur de Entre Ríos", Anales de la Facultad de Ciencias de la Educación 3, pp. 1-63.

Aparicio, F. (1936) “El Paraná y sus tributarios”. En: Junta de Historia y Numismática Americana (ed.) Historia de la Nación Argentina 1, Buenos Aires, Imprenta de la Universidad de Buenos Aires, pp. 473-506.

Apolinaire, E. (2017) Arqueología del suroeste de Entre Ríos: tecnología, subsistencia e interacción social en tiempos prehispánicos. Tesis doctoral inédita, La Plata, Facultad de Ciencias Naturales y Museo, Universidad Nacional de La Plata.

Apolinaire, E., Bastourre, L. \& Costa Angrizani, R. (2016) "Arqueología de las tierras altas de Entre Ríos: primeros resultados de las prospecciones en el interior del departamento Gualeguay”, Intersecciones en Antropología 17, pp. 91-107.

Badano, V. (1940) "Piezas Enteras de Alfarería del Litoral existentes en el Museo de Entre Ríos”, Memorias del Museo de Entre Ríos 14, pp. 4-16.

Balducci, F., Galligani, P. \& Sartori, J. (2016) “Tejiendo redes: el uso de fuentes históricas y etnográficas para el abordaje del registro arqueobotánico en la planicie de inundación del río Paraná”, Anuario de Arqueología 8, pp. 79-99.

Barboza, C. (2014) “Análisis arqueofaunístico del sitio Paso del Tala (Goya, Corrientes, Argentina)”, Revista del Museo de Antropología 7(2), pp. 219-226.

Barboza, M.C. \& Píccoli, C.V. (2013) "Ocupaciones humanas en la llanura aluvial del Paraná medio durante el Holoceno tardío. El registro arqueológico del sitio Los Bananos (Goya, Corrientes, Argentina)”, Anuario de Arqueología 5, pp. 117-132.

Bastourre, L. (2014) "Estudios arqueofaunísticos en el Delta Superior del Paraná: el sitio Los Tres Cerros 1 (Provincia de Entre Ríos, Argentina)", Revista Chilena de Antropología 30, pp. 109-115.

Bastourre, L. (2018) "Del registro ictioarqueológico a las prácticas alimentarias: el caso de Los Tres Cerros 1 (Delta Superior del Paraná, Entre Ríos)”, Revista del Museo de La Plata, suplemento resúmenes 3(1), p. 107R.

Bó, R.F. (2006) "Situación ambiental en la ecorregión Delta e Islas del Paraná”. En: Brown, A., Martinez Ortiz, U., Acerbi, M. \& Corcuera, J. (eds.), La Situación Ambiental Argentina 2005, Buenos Aires, Fundación Vida Silvestre Argentina, pp. 131-143.

Bonetto, A.A. (1986) “The Paraná River System”. En: Davies, B. \& Walker, K.F. (eds.) The Ecology of River Systems, Dordrecht, Springer Science - Business Media, pp. 541-556.

Bonetto, A.A. (1998) "Revisión. Panorama sinóptico sobre la ictiofauna, la pesca y piscicultura en los ríos de la cuenca del Plata, con especial referencia al Paraná”, Revista de Ictiología 6(1/2), pp. 3-16.

Bonomo, M. (2006) "Un acercamiento a la dimensión simbólica de la cultura material en la región pampeana", Relaciones de la Sociedad Argentina de Antropología XXXI, pp. 89-115.

Bonomo, M. (2012) Historia prehispánica de Entre Ríos. Buenos Aires, Fundación de Historia Natural Félix de Azara, Universidad Maimónides.

Bonomo, M. (2013) "Reanálisis de la colección de Samuel Lothrop procedente del Delta del Paraná", Relaciones de la Sociedad Argentina de Antropología 38(1), pp. 169-198.

Bonomo, M. \& Blasi, A. (2010) "Base regional de recursos líticos del Delta del Paraná. Estudio petrográfico de artefactos y afloramientos en el sur de Entre Ríos”. Revista Cazadores Recolectores del Cono Sur 4, pp. 17-41.

Bonomo, M., Capdepont I \& Matarrese, A. (2009) Alcances y limitaciones en el estudio de colecciones. Los materiales arqueológicos del Delta del río Paraná depositados en el Museo de La Plata. Revista de Arqueología Sudamericana 5(1), pp. 68-101.

Bonomo, M., Politis, G. \& Gianotti, C. (2011a) "Montículos, jerarquía social y horticultura en las sociedades indígenas del Delta del río Paraná (Argentina)”, Latin American Antiquity 22(3), pp. 297-333.

Bonomo, M., Aceituno, F., Politis, G.G. \& Pochettino, M.L. (2011c) "Pre-Hispanic Horticulture in the Paraná Delta (Argentina): Archaeological and Historical Evidence”, World Archaeology 43(4), pp. 557-579. 
Bonomo, M., Colobig, M.M., Passeggi, E., Zucol, A. \& Brea, M. (2011b) "Multidisciplinary studies at Cerro Tapera Vázquez site, PreDelta National Park, Argentina: The archaeological, sedimentological and paleobotanical evidence", Quaternary Internacional 245 , pp. 48-61.

Bonomo, M., Colobig M.M., \& Mazzia, N. (2012) “Análisis de residuos orgánicos y microfósiles silíceos de la "cuchara” de cerámica del sitio arqueológico Cerro Tapera Vázquez (Parque Nacional Pre-Delta, Argentina)”, Revista do Museu de Arqueologia e Etnologia 22, pp. 31-50.

Bonomo, M., Castro, J.C. \& Silva, C.B. (2014) "Tecnología y subsistencia en el sitio arqueológico Cerro Tapera Vázquez (Parque Nacional Pre-Delta, República Argentina)”, Cuadernos do Lepaarq 11(22), pp. 53-81.

Bonomo, M., Angrizani, R., Apolinaire, E. \& Noelli, F.S. (2015) “A model for the Guaraní expansion in the La Plata Basin and littoral zone of southern Brazil”, Quaternary International 356, pp. 54-73.

Bonomo, M., Politis, G., Silva, C.B., Bastourre, L., Ramos van Rapp, M.A., Castiñeira, C., Scabuzzo, C. \& Apolinaire, E. (2016) "Estado actual de las investigaciones en la localidad arqueológica Laguna de los Gansos (Diamante, Entre Ríos)", Revista del Museo de Antropología 9(2), pp. 51-66.

Bonomo, M., Scabuzzo, C., Politis, G. \& Zucol, A. (2017a) "Stable Carbon and Nitrogen Isotope Studies in the Paraná River Delta (Argentina): An Approach to Prehispanic Diets", Latin American Antiquity 28(1), pp. 105-126.

Bonomo, M., Cabanillas, E. \& Montero, R. (2017b) "Archaeometallurgy in the Paraná Delta (Argentina): Composition, manufacture, and indigenous routes”, Journal of Anthropological Archaeology 47, pp. 1-11.

Bracco, R., Cabrera, L. \& López Mazz, J.M. (2000) “La Prehistoria de las Tierras Bajas de la Cuenca de la Laguna Merín”. En: Durán, A. \& Bracco, R. (eds.) Arqueología de las Tierras Bajas, Montevideo, MEC, pp. 13-38.

Brea, M., Franco, M.J., Bonomo, M. \& Politis, G.G. (2013) “Análisis antracológico preliminar del sitio arqueológico Los Tres Cerros 1 (Delta Superior del río Paraná), provincia de Entre Ríos”, Revista del Museo de La Plata 13(87), pp. 345-360.

Brochado, J.P. (1984) An Ecological Model of the Spread of Pottery and Agriculture into Eastern South America. Tesis doctoral inédita, Illinois, University of Illinois.

Brochado, J. P. \& Monticelli, G. (1994) "Regras práticas na reconstrução gráfica das vasilhas de cerâmica guarani a partir dos fragmentos”, Estudos Ibero-americanos 20(2), pp. 107-118.

Burkart, A. (1957) “Ojeada sinóptica sobre: La vegetación del Delta del Río Paraná”, Darwiniana 11(3), pp. 457-561.

Cabrera, A.L. (1953) "Esquema fitogeográfico de la República Argentina”, Revista del Museo de la ciudad Eva Perón, (NS) vol. VIII, Sección Botánica, pp. 87-168.

Caggiano, M.A. (1984) "Prehistoria del noreste Argentino, sus vinculaciones con la República Oriental del Uruguay y sur de Brasil”, Pesquisas, Antropología 38, pp. 1-109.

Caggiano, M.A. \& Flores, O.B. (2001) "La ocupación humana en el delta del Paraná, a propósito de nuevos fechados radiocarbónicos", XIV Congreso Nacional de Arqueología Argentina, Rosario, pp. 1-8..

Caggiano, M.A., Flores, O., Méndez, M.G. \& Salceda, S. (1978) "Nuevos aportes para el conocimiento antropológico del Delta del Paraná", Relaciones de la Sociedad Argentina de Antropología XII, pp. 155-174.

Campos, G.L. (2001) Análisis litogenético de la matriz sedimentaria de los sitios arqueológicos "La Lechuza" y "Puerto Perita”. Tesina de licenciatura inédita, Rosario, Facultad de Humanidades y Arte, Universidad Nacional de Rosario.

Canals Frau, S. (1940) "Los indios del Distrito de Buenos Aires. Publicaciones del Museo Etnográfico de la Facultad de Filosófia y Letras”, serie A, IV, pp. 5-39.

Capdepont, I. (2012) Arqueología de sociedades indígenas del litoral del río Uruguay. Tesis doctoral inédita, Olavarría, Facultad de Ciencias Sociales, Universidad del Centro de la Provincia de Buenos Aires.

Capdepont, I. \& Bonomo, M. (2010-2011) “Análisis petrográfico de material cerámico del Delta del Paraná”, Anales de Arqueología y Etnología 65-66, pp. 127-147.

Cardoso de Oliveira, R. (1960) O Processo de Assimilação dos TERÊNA, Rio de Janeiro, Museu Nacional Rio de Janeiro.

Castiñeira, C., Blasi, A., Politis, G., Bonomo, M., del Puerto, L., Huarte, R., Carbonari, J., Mari, F. \& García-Rodríguez, F. (2013) "Origin and Construction of Mounds in the Upper Paraná Delta Wetlands (Argentina)", Archaeological and Anthropological Sciences 5(1), pp. 37-57.

Castiñeira, C., Blasi, A., Bonomo, M., Politis, G. \& Apolinaire, E. (2014) “Modificación antrópica del paisaje durante el Holoceno 
tardío: las construcciones monticulares en el Delta Superior del río Paraná, Argentina", Revista de la Asociación Geológica Argentina 71(1), pp. 33-47.

Castiñeira, C., Apolinaire, E., Blasi, A., Bonomo, M., Politis, G., Bastourre, L. \& Mari, F. (2017a) "Pre-Hispanic Settlements in Hydrometeorologically Susceptible Areas during late Holocene: the Upper Delta of the Paraná River Case", The Holocene 27(12), pp. 1801-1811.

Castiñeira, C., Apolinaire, E., Blasi, A., Politis, G., Bonomo, M. \& Mari, F. (2017b) "Pre-Hispanic earthwork engineering variability in the Upper Delta of the Paraná River. A comparative study between Los Tres Cerros mounds (Entre Ríos province, Argentina)", Journal of Archaeological Science Reports 13, pp. 322-332.

Castro, A. (1926) Informe sobre expedición al Delta del Paraná, Arroyo La Glorieta, La Plata, 1926, Museo de La Plata.

Castro, C.C. (2017) "Reconstrucción de vasijas asociadas a contextos funerarios en el sitio Los Tres Cerros 1 -Delta Superior del río Paraná-", Comechingonia. Revista de Arqueología 21(2), pp. 125-144.

Castro, J.C. (2017) Investigaciones arqueológicas en la cuenca media e inferior del río Uruguay (provincia de Entre Ríos). Tesis doctoral inédita, La Plata, Facultad de Ciencias Naturales y Museo, Universidad Nacional de La Plata.

Castro, J.C. (2018) "La entidad arqueológica Goya-Malabrigo en el río Uruguay". En: Politis, G. \& Bonomo, M. (eds.) Nuevas perspectivas sobre la entidad arqueológica Goya-Malabrigo, Tandil. Editorial UNICEN, pp. 217-245.

Castro, J.C. \& Castiñeira, C. (2017) "Estudio de la secuencia sedimentaria de la localidad arqueológica Cerros de Boari (Gualeguaychú, Entre Ríos)", Comechingonia. Revista de Arqueología 21(2), pp. 75-97.

Cavallotto, J.L., Violante, R.A. \& Colombo, F. (2005) "Evolución y cambios ambientales de la llanura costera de la cabecera del Río de la Plata”, Revista de la Asociación Geológica Argentina 60(2), pp. 353-367.

Ceruti, C.N. (1981) “Proyecto Investigaciones arqueológicas en el área del Paraná Medio - margen entrerriana”. Resumen de actividades (período marzo 1978 a septiembre 1981). Ms.

Ceruti, C.N. (1984) "Proyecto Investigaciones arqueológicas en el área del Paraná Medio- margen entrerriana. Síntesis de los Avances a Noviembre de 1984”. Informe 73 Cod. 721. Paraná, Agua y Energía Eléctrica.

Ceruti, C.N. (1986) “Algo sobre crítica y autocrítica en Arqueología”, Revista de Antropología 1(1), pp. 19-24.

Ceruti, C.N. (1989) "Proyecto "Las modificaciones ambientales del Pleistoceno final Holoceno, y su relación con los asentamientos humanos en el noroeste de Entre Ríos" (PID-CONICET No 3081800/88)". Informe Final. Ms.

Ceruti, C.N. (1992) “Cambios climáticos y poblaciones prehispánicas en el Litoral argentino”, El Holoceno en Argentina 1, pp. $39-49$.

Ceruti, C.N. (1993) “Arqueología”. En: Renna, A. (ed.) Nueva Enciclopedia de la Provincia de Santa Fe IV, Santa Fe, Sudamérica, pp. 557-580.

Ceruti, C.N. (2003) “Entidades culturales presentes en la cuenca del Paraná Medio (margen entrerriana)”, Mundo de Antes 3, pp. 111135.

Ceruti, C.N. (2018). "Indicios de complejidad social en la entidad arqueológica Goya-Malabrigo: los enterratorios humanos del sitio La Palmera II (Hernandarias, departamento Paraná, provincia de Entre Ríos, Argentina)”. En Politis, G. \& Bonomo, M. (eds.), GoyaMalabrigo: arqueología de una sociedad indígena del noreste argentino, Tandil, Editorial UNICEN, pp. 149-173.

Ceruti, C.N. \& Crowder, R. (1973) "La presencia de cerámica en los cordones conchiles litorales de la Provincia de Buenos Aires (Argentina). Un sitio nuevo", Primer Congreso Nacional de Arqueología y Segundo Encuentro de Arqueología del Interior, Fray Bentos, p. 39.

Ceruti, C.N. \& Traver Borny, M.B. (2007) “Un aporte a la arqueología experimental: reproducción de material cerámico de la entidad Goya-Malabrigo”. En: Oliva, F., de Grandis, N. \& Rodríguez, J. (comps.) Arqueología Argentina en los Inicios de un nuevo siglo, tomo I, Rosario, Laborde Editor, pp. 251-258.

Ceruti, C., Fontana, O., López, L. \& Vesco, C. (1980) “Arroyo Arenal 4 (Dpto. La Paz, Pcia. de Entre Ríos). Un Hallazgo Arqueológico Poco Común”, Notas del Museo de Ciencias Naturales y de Antropología de Entre Ríos, Antropología, Nueva Serie 2, pp. 1-23.

Chiri, O.C. (1974) "La alfarería indígena en el Nordeste argentino según las referencias de algunas fuentes", Relaciones de la Sociedad Argentina de Antropología VIII, pp. 237-248.

Cigliano, E.M., Schmitz, P.I. \& Caggiano, M.A. (1971) "Sitios cerámicos prehispánicos en la costa septentrional de la provincia de Buenos Aires y de Salto Grande, Entre Ríos. Esquema tentativo de su desarrollo", Anales de la Comisión de Investigaciones Científicas de la provincia de Buenos Aires CXCII(II-III), pp. 131-191. 
Cione, A.L., Rizzo, A. \& Tonni, E.P. (1977) “Relación cultura indígena-medio ambiente en un sitio de Rincón de Landa, Gualeguaychú, Entre Ríos, República Argentina. Nota preliminar”, V Encuentro de Arqueología del Litoral, Fray Bentos, pp. 121-141.

Cocco, G. (2003) "Movilidad y uso del espacio de cazadores-recolectores en ambientes de ecotono: las investigaciones arqueológicas en el sector sur de la región del Bajo de los Saladillos, provincia de Santa Fe”, Revista América 16, pp. 71-76.

Cocco, G., Barboza, C. \& Ayuso, M.P. (2004) “La interpretación de registro bioarqueológico en el sector sur del Bajo de los Saladillos, provincia de Santa Fe”, Revista de la Escuela de Antropología 9, pp. 173-186.

Codignotto, J. O. \& Kokot, R. R. (2005) “Geomorfología del sector Litoral de la provincia de Buenos Aires”, XVI Congreso Geológico Argentino, La Plata, pp. 643-650.

Colobig, M.M. \& Ottalagano, F. V. (2016) "Estudio arqueobotánico de los residuos orgánicos adheridos en alfarerías prehispánicas de la cuenca del Paraná medio", Arqueología 22(1), pp. 193-210.

Colobig, M.M., Sánchez, J.O. \& Zucol, A. (2015) “Análisis de macrorrestos vegetales en el sitio arqueológico Los Tres Cerros 1 (isla Las Moras, Victoria, Entre Ríos)”, Revista del Museo de Antropología 8(1), pp. 115-124.

Colobig, M.M., Zucol, A. \& Silva, C.B. (2018) “Análisis de microrrestos de secuencias sedimentarias del sitio Laguna de los Gansos 1 y 2 (Delta Superior del río Paraná, Argentina)”. En: Politis, G. \& Bonomo, M. (eds.), Goya-Malabrigo: arqueología de una sociedad indígena del noreste argentino, Tandil, Editorial UNICEN, pp. 333-346.

Colobig, M.M., Zucol, A., Bonomo, M. \& Politis, G. (2014) "Estudios arqueobotánicos del sitio Laguna de los Gansos 1 (Delta Superior del río Paraná, Argentina): análisis de microrrestos vegetales en materiales cerámicos", Taller "Micro Paleoetnobotánica": Relevancia de una Red Interdisciplinaria de Investigaciones en Fitolitos y Almidones, La Paloma, Uruguay.

Coll, M. \& Katalinich, F. (2010) “Caracterización de la tecnofactura de los materiales cerámicos procedentes del sitio Boca del Seco (provincia de Santa Fe)”. En: Berón, M., Luna, L., Bonomo, M., Montalvo, C., Aranda, C. \& Carrera Aizpitarte, M. (eds.) Mamül Mapu: pasado y presente desde la arqueología pampeana II, Ayacucho, Libros del Espinillo, pp. 361-371.

Cornero, S. (2009) “Apuntes de arqueología de islas. Sitio El Castaño, boca de la Milonga, río Paraná”, Anuario de Arqueología 1(1), pp. 153-160.

Cornero, S. (2016) "Sitio La Lechuza: aportes para la investigación en la arqueología (norte de Santa Fe)" XIX Congreso Nacional de Arqueología Argentina, Tucumán, pp. 480-484.

Cornero, S. \& Cocco, G. (1995) “Arqueología de rescate sitio Isla Barranquita: informe preliminar”, Revista del Museo de Historia Natural de San Rafael XXVII(1/4), pp. 47-53.

Cornero, S. \& Puche, R. (2007) "Paleopatología en Argentina prehistórica. Salud y enfermedad entre los antiguos cazadores de Alejandra, Santa Fe, Argentina”. En: Sotomayor Tribín, H.A. \& Cuellar Montoya, Z. (eds.) Aproximaciones a la paleopatología en América Latina, Bogotá, Academia Nacional de Medicina de Colombia, pp. 149-165.

Cornero, S. \& Rangone, L. (2015) “Análisis arqueobotánicos en sitios de la entidad arqueológica Goya-Malabrigo ubicados en el centronorte de Santa Fe", Anuario de Arqueología 7, pp. 85-94.

Cornero, S., Solomita, F. \& Curetti, P. (2007) "Componente arqueofaunístico del sitio La Lechuza (provincia de Santa Fe)", XIV Congreso Nacional de Arqueología Argentina 1, Mar del Plata, 167-171.

Covarrubias Horozco, S. de ([1611] 2006) Tesoro de la lengua española. En: Arellano, I. \& Zafra, R. (eds.). Madrid/Vervuert, Frankfurt am Main, Iberoamericana.

David, N., Sterner, J. \& Gavua, K. (1988) "Why Pots Are Decorated”, Current Anthropology 29(3), pp. 365-389.

Del Papa, M., Scabuzzo, C., Ramos van Raap, M.A., Bonilla, D. \& Pennini, V. (2016) "Nuevos análisis bioarqueológicos de la colección osteológica del sitio Paraná Ibicuy 1 (Delta Inferior del Río Paraná, Entre Ríos)”, Intersecciones en Antropología 17, pp. $263-267$.

Di Prado, V. (2015) Estudio comparativo de las prácticas de elaboración y uso de la alfarería prehispánica del centro-este de Argentina desde una perspectiva macrorregional. Tesis doctoral inédita, La Plata, Facultad de Ciencias Naturales y Museo, Universidad Nacional de La Plata.

Di Prado, V. (2016) "Primeras etapas de elaboración cerámica en Los Tres Cerros 1 (Victoria, Entre Ríos). Caracterización mediante petrografía de pastas", Intersecciones en Antropología 3, pp. 23-32.

Di Prado, V. (2018) "Prácticas alfareras prehispánicas y procesos de interacción social en el centro-este de Argentina durante el Holoceno tardío". Latin American Antiquity 29(3), pp. 552-571.

Di Prado, V. \& Castro, C. (2014) "Estrategia de remontajes aplicada sobre el registro cerámico del sitio Los Tres Cerros 1 (Delta Superior del Paraná)", Revista del Museo de Antropología 7(2), pp. 263-270. 
Drago, E.C. (1990) "Hydrological and geomorphological characteristics of the hydrosystem of the Middle Paraná river", Acta Limnologica Brasiliensia III, pp. 907-930.

Echegoy, C. (1994) Los fechados C14 de Arroyo Aguilar. Arqueología del Paraná 2. Reconquista, Museo Municipal de Arqueología y Paleontología de Reconquista.

Edith, R. (1985) "Theoretical and practical considerations in the analysis of anthrosols". En: Rapp, G. \& Gifford, J. (eds) Archaeological geology, New Haven, Yale University Press, pp.155-190.

Eremites de Oliveira, J. (1996) Guató: argonautas do pantanal. Coleção Arqueologia 2, Porto Alegre, EDIPUCRS.

Erickson, C.L. (2000) “Lomas de ocupación en los Llanos de Moxos, Bolivia”. En: Durán, A. \& Bracco, R. (eds.) Arqueología de las Tierras Bajas, Montevideo, MEC Americana, pp. 207-226.

Erickson, C.L. (2009) "Agency, Causeways, Canals, and the Landscapes of Everyday Life in the Bolivian Amazon". En: Snead, J., Erickson, C. \& Darling, A. (eds.) Landscapes of Movement. Trails, Paths, and Roads in Anthropological Perspective, Philadelphia, University of Pennsylvania Press, pp. 204-231.

Escudero, S. \& Feuillet Terzaghi, M.R. (2002) "El registro arqueofaunístico del sitio Bajada Guereño (Prov. de Santa Fe). Implicancias en el aprovechamiento de vertebrados". XXII Encuentro de Geohistoria Regional del Nordeste Resistencia.

Escudero, S., Feuillet Terzaghi, M.R. \& Núñez Camelino, M. (2011) "Modelos teóricos imperantes en la arqueología del nordeste argentino: los casos de las provincias de Corrientes y Santa Fe (Argentina)", Arqueología 17, pp. 97-118.

Fernández de Oviedo y Valdés, G. (1851-1855 [1546-1547]) Historia general y natural de las Indias, Islas y Tierra Firme del Mar Océano, Libro XXIII. Guarania, Asunción del Paraguay.

Feuillet Terzaghi, M.R. (2009) El Registro Bioarqueológico de la Cuenca Inferior del Río Salado y Cuenca del Río Coronda (Margen Derecha, provincia de Santa Fé). Tesis doctoral inédita, Rosario, Facultad de Humanidades y Artes, Universidad Nacional de Rosario.

Feuillet Terzaghi, M.R. \& Escudero, S. (2006) "Estudios tecno-morfológicos en la cerámica del sitio Isleta del Árbol Viejo (Dpto. San Jerónimo, Pcia. de Santa Fe, Argentina)”. XXVI Encuentro de Geohistoria Regional, Resistencia, pp.161-165.

Frenguelli, J. \& de Aparicio, F. (1923) "Los paraderos de la margen derecha del río Malabrigo (departamento de Reconquista, Prov. de Santa Fé)", Anales de la Facultad de Ciencias de la Educación 1, pp. 7-112.

Fried, M.H. (1967) The Evolution of Political Society. New York, Random House.

Gaggero, P. (1921) Informe elevado a L. Ma. Torres sobre expedición al Delta del Paraná, Arroyo Fredes, La Plata, 8 de julio de 1921, Museo de La Plata.

Gaggero, P. (1925) Informe elevado a L. Ma. Torres sobre expedición al Delta del Paraná, Arroyo Malo, La Plata, 5 de marzo de 1925, División Antropología del Museo de La Plata.

García, A.M. (2017) Reconhecendo diferentes fenômenos de Cerritos no Rio Grande do Sul. Tesis doctoral inédita, Rio de Janeiro, Museu Nacional Universidade Federal do Rio de Janeiro.

Galligani, P., Balducci, F., Sartori, J. \& Riberi, M. (2018) “Análisis del registro cerámico desde una perspectiva tafonómica: el caso de los sitios arqueológicos Familia Primón y Los Bañados (centro-este de Santa Fe, Argentina)”, Mundo de Antes 12(1), pp. 107-133.

Gaspar, M.D. (2014) “Sambaquis Shell Mounds, Archaeology of”. En: Smith, C. (ed.) Encyclopedia of Global Archaeology, New York, Springer, pp. 6449-6454.

Gaspary, F. (1945) “Las campanas chaná-timbúes”, Revista Geográfica Americana XXIII(140), pp. 279-282.

Gaspary, F. (1950) "Investigaciones Arqueológicas y Antropológicas en un cerrito de la Isla Los Marinos (Pcia. De Entre Ríos)", Publicación del Instituto de Arqueología, Lingüistica y Folklore 23, pp. 3-66.

Gatto, S. (1939) “El paradero-cementerio de Brazo Largo (Delta del Paraná)”, Physis XVI, pp. 365-376.

Gianotti, C. (2016) Paisajes sociales, monumentalidad y territorio en las tierras bajas de Uruguay. Tesis doctoral inédita, Santiago de Compostela, Universidad de Santiago de Compostela.

Gianotti C. \& M. Bonomo (2013) "De montículos a paisajes: procesos de transformación y construcción de paisajes en el sur de la cuenca del Plata", Comechingonia. Revista de Arqueología 17, pp. 59-94.

Giraudo, A.R. \& Arzamendia, V. (2004) “ ¿Son los humedales fluviales de la Cuenca del Plata corredores de biodiversidad? Los amniotas como ejemplo”. En: Neiff, J.J. (ed.) Humedales de Iberoamérica, La Habana, Red Iberoamericana de Humedales, pp. 153-170. 
González, A. (1947) Investigaciones arqueológicas en las nacientes del Paraná Pavón. Córdoba, Universidad Nacional de Córdoba.

Howard, G.D. \& Willey, G. (1948) Lowland Argentine Archaeology. New Haven, Yale University Publications in Anthropology 39. Yale University Press.

Iriarte, J., Deblasis, P., de Souza, J.G. \& Corteletti, R. (2017a) “Emergent Complexity, Changing Landscapes, and Spheres of Interaction in Southeastern South America During the Middle and Late Holocene", Journal of Archaeological Research 25(3), pp. 251-313.

Iriarte, J. Smith, R.J. de Souza, J.G., Mayle, F.E., Whitney, B.S., Cárdenas, M.L., Singarayer, J., Carson, J. F. Roy, S. \& Valdes, P. (2017b) "Out of Amazonia: Late-Holocene climate change and the Tupi-Guarani trans-continental expansion", The Holocene 27(7), pp. 967-975.

Iribarne, E.A. (1937) “Algunos vasos indígenas de las márgenes del Paraná inferior”, Relaciones de la Sociedad Argentina de Antropología I, pp. 181-194.

Iriondo, M.H. (2004). “The littorla complex at the Paraná mouth”, Quaternary International 114, pp. 143-154.

Iriondo, M.H. (2007). “Geomorphology”. En: Iriondo, M.H., Paggi, J.C. \& Parma, M.J. (eds.) The Middle Paraná River: Limnology of a Subtropical Wetland, Berlín, Springer, pp. 33-52.

Iriondo, M.H., Paggi, J.C. \& Parma, M.J. (2007). “Introduction”. En: Iriondo, M.H., Paggi, J.C. \& Parma, M.J. (eds.) The Middle Paraná River: Limnology of a Subtropical Wetland, Berlín, Springer, pp. 1-4.

Kozameh, L. (2009) "Un ejemplo de dentistería prehistórica en un resto humano del Delta del Paraná". En Oliva, F. de Grandis, N. \& Rodríguez, J., Arqueología Argentina en los inicios de un nuevo siglo II, Rosario, Universidad Nacional de Rosario, pp. 59-65.

Kozameh, L., Testa, N., López, M., Mango, L. \& Cornaglia Fernández, J. (2018) “Huesos rojos en el Delta superior del río Paraná. El caso del sitio arqueológico Cerro Grande de la "Isla los Marinos" (Entre Ríos, Argentina)". En: Politis, G. \& Bonomo, M. (eds.), Goya-Malabrigo: arqueología de una sociedad indígena del noreste argentino, Tandil, Editorial UNICEN, pp. 129-148.

Kozameh, L. \& Brunás, O.M. (2009) "Rastro de proceso osteomielítico en una clavícula". Puentes y Transiciones, Libro de Resúmenes del III Congreso de la Asociación de Paleopatología en Sudamérica, pp. 94. Necochea.

Kozameh, L. \& Brunás, O.M. (2013) "Enfermedad de Paget en un individuo prehispánico del Delta del Paraná, confirmado por examen histológico y datación radiocarbónica", Cuadernos del Instituto Nacional de Antropología y Pensamiento Latinoamericano, Series Especiales 1(1), pp. 114-120.

Kozameh, L., López, M., Testa, N. \& Mazza, B. (2007) “Los cazadores-recolectores de Cerro Lutz, (sudeste de Entre Ríos). Indicadores esqueletales de actividades cotidianas". Actas XVI Congreso Nacional de Arqueología, Resúmenes expandidos I, pp. 183-188. San Salvador de Jujuy.

Lafon, C.R. (1971) “Introducción a la Arqueología del Nordeste argentino”. Relaciones de la Sociedad Argentina de Antropología 5(2), pp. $119-152$.

Lafon, C.R. (1972) “El replanteo para la arqueología del Nordeste argentino”. Antiquitas 14, pp. 1-16.

Letieri, F.C. \& Alonso, A. (2004) “Aspectos tecnológicos presentes en el proceso de producción cerámica: sitio Bajada Guereño, ciudad de Villa Gobernador Gálvez, provincia de Santa Fe". En: Gradín, C. \& Oliva, F. (eds.), La Región Pampeana -su pasado arqueológico-, Rosario, Universidad Nacional de Rosario, pp. 321-335.

Letieri, F., Escribano Ruiz, S., Pasquali, C., Azkarate, A., Cocco, G., Sánchez Pinto, I. \& De La Fuente, G. (2015) “Approaching the Cultural Complexity of Pottery from Sancti Spiritus Village and Fort (Puerto Gaboto, Argentina)". En: Buxeda i Garrigós, J., Madrid i Fernández, M. \& Iñañez, J.G. (eds.), Global Pottery 1. Historical Archaeology and Archaeometry for Societies in Contact, Oxford, British Archaeological Reports, pp. 241-252.

Lista, R. (1878) “Les cementières et paraderos minuanes de la province de Entre Ríos”. Revued'Anthropology 7, pp. 365-368.

López, H. (2001) "Estudio y uso sustentable de la Biota Austral: Ictiofauna Continental Argentina”. Revista Cubana de Investigaciones Pesqueras (suplemento especial versión electrónica), pp. 1-40.

López Mazz J. (2018) “Contextos arqueológicos Goya-Malabrigo en la cuenca oriental del río Uruguay”. En Politis, G. \& Bonomo, M. (eds.), Goya-Malabrigo: arqueología de una sociedad indígena del noreste argentino, Tandil, Editorial UNICEN, pp. $269-288$.

López Mazz J., Rostain, S. \& Mckey, D. (2016) “Cerritos, Tolas, Tesos, Camellones y otros montículos de las tierras bajas de Sudamérica”. Revista de Arqueologia 29(1), pp. 86-113.

Loponte, D. (2008) “Arqueología del Humedal del Paraná Inferior (Bajíos Ribereños Meridionales)”. Asociación Amigos del Instituto Nacional de Antropología y Pensamiento Latinoamericano, pp. 478. Buenos Aires. 
Loponte, D. \& Acosta, A. (2015) "Los sitios arqueológicos Túmulo de Campana 1 y 2 dentro del contexto regional del humedal del Paraná inferior”. Revista de Antropología del Museo de Entre Ríos 1(2), pp. 11-40.

Loponte, D., Acosta, A. \& Mucciolo, L. (2012) “Contribución a la arqueología del Delta del Paraná: el nivel acerámico del sitio Isla Lechiguanas 1". Comechingonia. Revista de Arqueología 16, pp. 207-246.

Loponte, D., Acosta, A. \& Tchilinguirián, P. (2016) "Estructuras "monticulares", unidades arqueológicas y falsas premisas en la arqueología del Noreste argentino". Anuario de Arqueología 8, pp. 45-78.

Lothrop, S.K. (1932) "Indians of the Paraná Delta, Argentina”. Annals of the New York Academy of Science 32, pp. 77-232.

Madero, E. (1902) Historia del Puerto de Buenos Aires. Buenos Aires, La Nación.

Malvárez, A.I. (1997) Las comunidades vegetales del Delta del río Paraná. Su relación con factores ambientales y patrones del paisaje, Tesis doctoral, Buenos Aires, Universidad de Buenos Aires.

Mazza, B. (2010) “Avances en el conocimiento de los entierros secundarios del humedal del Paraná inferior”. En: Bárcena, J.R. \& Chiavazza, H. (eds.), Arqueología Argentina en el Bicentenario de la Revolución de Mayo II, Mendoza, Zeta Editores, pp. 665-669.

Mazza, B. \& Loponte, D. (2012) “Las prácticas mortuorias en el humedal del Paraná inferior”. Arqueología Iberoamericana 13, pp. 321.

Mazza, B., Acosta, A. \& Loponte, D. (2016) "Nuevos datos para las Inhumaciones en urnas de sitios arqueológicos guaraníes del extremo meridional de la cuenca del Plata". Revista Chilena de Antropología 34, pp. 81-96.

Meggers, B., Dias, O.F., Miller, E.Th. \& Perota, C. (1988) "Implications of archaeological distributions in Amazonia". Workshop on Neotropical Distribution Patterns. Rio de Janerio, Academia Brasileira de Ciências, pp. 275-294.

Métraux, A. (1927). "Les migrations historiques des tribus Tupi-Guarani”. Journal de la Société dés Américanistes 19, pp. 1-45.

Métraux, A. (1934) "El estado actual de nuestros conocimientos sobre la extensión primitiva de la influencia guaraní y arawak en el continente sudamericano", Actas y Trabajos Científicos del XXV Congreso Internacional de Americanistas I, La Plata, Universidad Nacional de La Plata, pp. 181-190.

Milheira, R.G. \& Gianotti, C. (2018) "The Earthen Mounds (Cerritos) of Southern Brazil and Uruguay". En Smith, C. (ed.), Encyclopedia of Global Archaeology, Switzerland, Springer Nature, pp. 1-9. https://doi.org/10.1007/978-3-319-51726-1_3025-1

Muñiz F.J. (1825) “Noticia sobre las yslas del Parana”. Publicaciones del Instituto de Investigaciones Geográficas 9, pp. 15-24.

Neiff, J.J. (1990) “Ideas para la interpretación ecológica del Paraná”. Interciencia 15(6), pp. 424-441.

Neiff, J.J. (2005) "Bosques fluviales de la cuenca del Paraná". En Arturi, M.F., Frangi, J.L. \& Goya, J.F. (eds.), Ecología y manejo de los bosques de Argentina, La Plata, Edición Multimedia, pp. 1-26.

Neumann, M. A. (2008) Ñanderekó: diferentes jeitos de ser Guarani, Tesis de maestría, Rio Grande do Sul, Universidade Federal do Rio Grande do Sul.

Nimuendajú, C. (1982) Mapa etno-histórico de Curt Nimuendajú. Rio de Janeiro, IBGE/ Fundação Nacional Pró-Memória.

Nóbile, J. (2002) “Asentamiento y subsistencia en la llanura aluvial del río Paraná (Sector Bajo Paraná): aproximaciones a un modelo regional”. En: Cavellini, S., Curbelo, C., Geymonat, J., Pintos, S., Marenales, M., Moreno, M. \& Rolando, G. (eds.), Arqueología Uruguaya hacia el fin del Milenio 1, Montevideo, Gráficos del Sur, pp. 187-193.

Noelli, F. (1993) Sem tekohá não há tekó (em busca de um modelo etnoarqueológico da aldeia e da subsistencia Guarani e sua aplicação a uma área de domínio no delta do rio Jacuí-RS), Tesis de maestría, Rio Grande do Sul, Pontifícia Universidade Católica do Rio Grande do Sul.

Nordenskiöld, E. ([1916] 2009) "Indian Adaptations in Flooded Regions of South America (Introduction Denevan, W.)". Journal of Latin American Geography 8(2), pp. 209-224.

Nordenskiöld, E. ([1930] 2017) Arqueología de la cuenca del Amazonas, La Paz, Plural.

Ottalagano, F.V. (2009) Aproximaciones al Simbolismo de los Grupos Cazadores-Recolectores de las Tierras Bajas del Paraná Medio: Un abordaje contextual del Arte Mobiliar Cerámico, Tesis doctoral, Rosario, Universidad Nacional de Rosario.

Ottalagano, F.V. (2013) “The pre-Hispanic ceramic technology of South American hunter-gatherers (Paraná River Delta, Argentina): a preliminary archaeometric study”. Archaeological and Anthropological Sciences 5, pp. 59-68.

Ottalagano, F.V. \& Pérez, M. (2013) "Estudios petrográficos comparativos: un acercamiento regional a la tecnología cerámica del delta del Paraná”. Cuadernos del Instituto Nacional de Antropología y Pensamiento Latinoamericano, Series Especiales 1(2), pp. 79-94. 
Ottalagano, F., Darigo, M., Pereyra, B., Brancatelli, C. \& Iannelli, L. (2015) “Investigaciones arqueológicas en el sitio La Palmera 2 (cuenca del Paraná medio, provincia de Entre Ríos, Nordeste de Argentina)". Revista de Antropología del Museo de Entre Ríos 1(1), pp. 55-65.

Outes, F.F. (1912) “Cráneos indígenas del departamento de Gualeguaychú (Prov. de Entre Ríos)”. Anales de la Sociedad Científica Argentina 73, pp. 5-37.

Outes, F.F. (1918a) "Nuevo jalón septentrional en la dispersión de las representaciones plásticas de la cuenca paranaense y su valor indicador". Anales de la Sociedad Cientifica Argentina 85, pp. 53-66.

Outes, F.F. (1918b) "Nuevos rastros de la cultura Guaraní en la cuenca del Paraná inferior". Anales de la Sociedad Científica Argentina LXXXV, pp. 153-182.

Pauketat, T. R. (2004) Ancient Cahokia and the Mississippians. Cambridge, Cambridge University Press.

Peixoto, J.L.S. (2005) "Relação entre os Aterros e níveis hidrológicos do rio Paraguai, Pantanal”. XIII Congresso da Sociedade Brasileira de Arqueologia, Campo Grande.

Pérez Jimeno, L. (2007) Investigaciones arqueológicas en el sector septentrional de la llanura aluvial del Paraná, margen santafesina. La variabilidad del registro arqueológico, Tesis doctoral, La Plata, Universidad Nacional de La Plata.

Pérez, M., Loponte, D., Capparelli, I., Montenegro, T. \& Russo, N. (2009) "Estudo petrográfico da tecnologia cerâmica guarani no extremo sul de sua distribução: rio Paraná inferior e estuário do Rio da Prata, Argentina". Revista da Sociedade de Arqueologia Brasileira 22(1), pp. 65-82.

Pérez, M., Acosta, I., Naranjo, G. \& Malec, L. (2015) "Experimentación y análisis de ácidos grasos. Un acercamiento a la funcionalidad de la cerámica arqueológica del Humedal del Paraná Inferior”. Cuadernos del Instituto Nacional de Antropología y Pensamiento Latinoamericano, Series Especiales 2(4), pp. 38-55.

Pestana, M.B. (2007) A tradição Tupiguarani na porção central da planicie costeira do Rio Grande do Sul, Brasil, Dissertação, Mestrado em História, Unisinos, São Leopoldo.

Píccoli, C.V. (2014) Estudios de los paisajes arqueológicos en el sector de islas y borde frontal de la terraza baja de la llanura aluvial del Paraná Medio. Departamento Goya, Tesis doctoral, Rosario, Universidad Nacional de Rosario.

Píccoli, C.V. \& Barboza, C. (2016) "Empleo de análisis de correspondencias en el estudio de conjuntos cerámicos fragmentarios del Paraná medio". Cuadernos del Instituto Nacional de Antropología y Pensamiento Latinoamericano 25(1), pp. 94-111.

Píccoli, C.V. \& Barboza, C. (2018) "Las exploraciones de Lilia Spinelli en los inicios de la arqueología en el Nordeste argentino". En: Politis, G. \& Bonomo, M. (eds.), Goya-Malabrigo: arqueología de una sociedad indígena del noreste argentino, Tandil, Editorial UNICEN, pp. 45-71.

Podgorny, I. (2010) “Los médicos de muertos y la paleontología en el Plata. Medicina legal, cirugía militar y observación de campo en la obra de Francisco X. Muñiz, 1830-1850”. Anuario IEHS 25, pp. 305-332.

Politis, G. \& Bonomo, M. (2012) “La entidad arqueológica Goya-Malabrigo (Ríos Paraná y Uruguay) y su filiación Arawak”. Boletín de la Sociedade de Arqueología Brasileira 25(1), pp. 10-46.

Politis, G. \& Bonomo, M. (eds.) (2018a) Goya-Malabrigo: arqueología de una sociedad indígena del noreste argentino. Tandil, Editorial UNICEN.

Politis, G. \& Bonomo, M. (2018b) "Estado actual y perspectivas de Goya-Malabrigo, una sociedad indígena del Noreste argentino". En Politis, G. \& Bonomo, M. (eds.), Goya-Malabrigo: arqueología de una sociedad indígena del noreste argentino, Tandil, Editorial UNICEN, pp. 9-44.

Politis, G., Bonomo, M., Castiñeira, C. \& Blasi, A. (2011) “Archaeology of the Upper Delta of the Paraná River (Argentina): Mound Construction and Anthropic Landscapes in the Los Tres Cerros locality". Quaternary International 245, pp. 74-88.

Politis, G., Domic, A.I., Bonomo, M \& Capriles, J. (2018) "Modelamiento de los parámetros ambientales de la distribución de GoyaMalabrigo mediante Maxent”. En Politis, G. \& Bonomo, M. (eds.), Goya-Malabrigo: arqueología de una sociedad indígena del noreste argentino, Tandil, Editorial UNICEN, pp. 289-305.

Politis, G., Di Prado, V., Bastourre, L., Bonomo, M., Matarrese, A. \& Moreira, G. (2017) “Análisis de la colección del Túmulo II de Brazo Largo (Islas del Ibicuy, provincia de Entre Ríos)”. Revista del Museo de Antropología 10(2), pp. 71-88.

Ramos van Raap, M.A. (2018a) Paleopatología en poblaciones prehispánicas del sur del Noreste Argentino, Tesis doctoral, La Plata, Universidad Nacional de La Plata.

Ramos van Raap, M.A. (2018b) “Caracterización del registro mortuorio de la entidad arqueológica Goya-Malabrigo”. En Politis, G. \& 
Bonomo, M. (eds.), Goya-Malabrigo: arqueología de una sociedad indígena del noreste argentino, Tandil, Editorial UNICEN, pp. 175-199..

Ramos van Raap, M.A. \& Bonomo, M. (2016) "Nuevos estudios de la colección bioarqueológica de los sitios Arroyo Malo, El Cerrillo y Arroyo Sarandí (Delta del Paraná)”. Intersecciones en Antropología 3, pp. 71-82.

Ramos van Raap, M.A. \& Scabuzzo, C. (2018a) "A case of non-venereal treponematosis (possibly venereal syphilis) in a Pre-Hispanic adult from Northeastern Argentina". International Journal of Osteoarchaeology 28(6), pp. 757-765.

Ramos van Raap, M.A. \& Scabuzzo, C. (2018b) "Estudios bioarqueológicos de la colección del Museo Arqueológico Manuel Almeida (provincia de Entre Ríos)". Relaciones de la Sociedad Argentina de Antropología XLIII(2), pp. 185-205.

Rocchietti, A.M., de Grandis, N., Vicioso, V., Baruscia, J. \& Martínez, L. (1997) "La boca del arroyo Monje: los indios isleros y la invasión europea en siglo XVII”. Jornadas de Antropología de la Cuenca del Plata II, Rosario, Escuela de Antropología, UNR, pp. 188-195.

Rodríguez, J.A. (2001) "Poblamiento prehistórico de la Mesopotamia Argentina”. Folia Histórica del Nordeste 15, pp. 129-146.

Rodríguez, J.A. \& Rodríguez, A.A. (1985) Proyecto Antropológico-Ecológico Salto Grande (Primer Informe). Concordia, Universidad Nacional de Entre Ríos.

Rodríguez, J.A. \& Ceruti, C.N. (1999) “Las tierras bajas del Nordeste y litoral mesopotámico”. En: Academia Nacional de la Historia (ed.), Nueva Historia de la Nación Argentina I, Buenos Aires, Planeta, pp. 109-133.

Rossetti, D.F., Góes, A.M. \& Mann de Toledo, P. (2008) “Archaeological Mounds in Marajó Island in Northern Brazil: A Geological Perspective Integrating Remote Sensing and Sedimentology”. Geoarchaeology: An International Journal 24(1), pp. $22-41$.

Sánchez, J.O., Colobig, M.M., Zucol, A.F., Politis, G.G., Bonomo, M. \& Castiñeira, C. (2013) "Primeros resultados sobre el uso prehispánico de los vegetales en el sitio arqueológico Los Tres Cerros 1 (Victoria, Entre Ríos, Argentina): análisis del registro biosilíceo". Darwiniana, nueva serie 1(2), pp. 201-219.

Sartori, J. (2015a) "Pasado y presente de las investigaciones Arqueológicas en el sitio Las Tejas (Sante Fe, Argentina)". Revista de Antropología del Museo de Entre Ríos 1(2), pp. 109-120.

Sartori, J. (2015b.) "La información etnográfica y etnológica como marco interpretativo para contextos zooarqueológicos en la Llanura Aluvial del Paraná (Santa Fe, Argentina)”. Revista del Museo de Antropología 8(2), pp. 77-90.

Sartori, J. \& Galligani, P. (2014) "Zooarqueología en el humedal de la cuenca fluvial del centro este santafesino". Relaciones de la Sociedad Argentina de Antropología 39(2), pp. 387-409.

Sartori, J., Scuizzatto, F. \& Galligani, P. (2013) “Análisis comparativo de la tecnomorfología cerámica de los sitios de la cuenca media e inferior del río Coronda”. Cuadernos del Instituto Nacional de Antropología y Pensamiento Latinoamericano, Series Especiales 1(2), pp. 107-119.

Sastre, M. ([1856] 2010) El Tempe Argentino, Buenos Aires, Editorial del cardo. Disponible en http://biblioteca.arg.ar/libros/154414.pdf (Accedido 01 de septiembre 2017).

Scabuzzo, C. \& Di Lorenzo, B. (2017) "Modalidades inhumatorias y tratamiento de los cuerpos en el sitio Los Tres Cerros 1 (Delta Superior de Paraná)”. VII Encuentro de Discusión Arqueológica del Nordeste Argentino, Revista Scientia Interfluvius, Diamante, pp. 57.

Scabuzzo, C. \& Ramos van Raap, M.A. (2017) "Nuevos resultados de los estudios osteológicos del sitio Los Tres Cerros 1 (Delta Superior del río Paraná)”. Comechingonia. Revista de Arqueología 21(2), pp. 201-228.

Scabuzzo, C. \& Ramos van Raap, M.A. (2019) “Alcances y limitaciones en el relevamiento de osteoartrosis. Primeros resultados de los análisis en colecciones osteológicas del sur del Noreste argentino”. En Fabra, M., Novellino, P., Arrieta, M. \& Salega, S. (eds.), Metodologías para el estudio de restos esqueletales en Argentina: actualizaciones y nuevas perspectivas, Córdoba, Universidad Nacional de Córdoba. En prensa.

Scabuzzo, C., Ramos van Raap, M.A., Bonomo, M. \& Politis, G. (2015) "Estudios bioarqueológicos en el sitio Los Tres Cerros 1 (Delta Superior del río Paraná, Entre Ríos, Argentina)”. Boletim do Museu Paraense Emílio Goeldi, Ciências Humanas 10(2), pp- 487518.

Schaan, D.P. (2012) Sacred Geographies of Ancient Amazonia: Historical Ecology of Social Complexity. New Frontiers in Historical Ecology 3, Walnut Creek, Left Coast Press..

Schmidel, U. ([1567] 2009) Viaje al Río de La Plata. Traducido por Samuel Lafone Quevedo, Buenos Aires, Claridad.

Schmidt, M. (1912) “Reisen in Matto Grosso im Jahre 1910”. Zeitschrift für Ethnologie 44(1), pp. 130-174. 
Schmitz, P., Ceruti, C., González, A.R. \& Rizzo, A. (1972) "Investigaciones arqueológicas en la zona de Goya (Corrientes) Argentina". Dédalo 15.

Schmitz, P.I,. Rogge, J.H., Rosa, A.O., Beber, M.V. \& Mauhs, J. (2004) “Arqueologia do Pantanal em 2003”. XII Congresso da Sociedade de Arqueologia Brasileira, São Paulo.

Sempé, M.C., Paleo, M.C. \& Pérez Meroni, M. (1999) "Contacto Hispáno-indígena en la ribera occidental del Río de la Plata, siglos XVII-XVIII. Su interacción”. Investigaciones y Ensayos 49, pp. 457-478.

Serrano, A. (1922) "Sobre un nuevo procedimiento en la técnica alfarera del litoral”. Prometeo 1(16), pp. 3-7.

Serrano, A. (1930). "Un nuevo tipo de instrumento de piedra del litoral argentino". Revista de la Sociedad de Amigos de la Arqueología 4, pp. 205-209.

Serrano, A. (1941) "Clasificación de los aborígenes argentinos". Revista de la Universidad Nacional de Córdoba 27(9-10), pp. 3-33.

Serrano, A. (1950) Los primitivos habitantes de Entre Ríos, Paraná, Ediciones de la Biblioteca Entrerriana “General Perón”. Serie II..

Serrano, A. (1972) Líneas fundamentales de la arqueología del litoral (una tentativa de periodización). Córdoba, Instituto de Antropología XXXII.

Silva, C.B (2017) "Evaluación de los procesos de formación de sitio desde la alfarería: el caso de Laguna de los Gansos 1 (Dpto. Diamante, Entre Ríos)”. Comechingonia, Revista de Arqueología 21(2), pp. 145-174.

Silva, C.B. (2018) "Formas cerámicas Goya-Malabrigo: variabilidad y tipos morfológicos”. En Politis, G. \& Bonomo, M. (eds.), GoyaMalabrigo: arqueología de una sociedad indigena del noreste argentino, Tandil, Editorial UNICEN, pp. 73-87.

Soldano, F.A. (1947) Régimen y aprovechamiento de la red fluvial argentina. I: el río Paraná y sus tributarios, Buenos Aires, Cimera.

Steward, J. (1944-1949) South American Cultures: An Interpretative Summary. En Steward, J. (ed.), Handbook of South American Indians 5, Washington D.C., Bureau of American Ethnology, Bulletin 143, U.S. Government Printing Office, pp. 669-818.

Torres, L.M. (1903) "Los cementerios indígenas del sur de Entre Ríos y su relación con los del Uruguay, Túmulos de Campana (Buenos Aires) y Santos (Brasil)”. Anales del Museo Nacional de Buenos Aires 3(2), pp. 57-73.

Torres, L.M. (1911) Los primitivos habitantes del Delta del Paraná. Buenos Aires, Buenos Aires, Universidad Nacional de La Plata, Biblioteca Centenaria.

Urban, G. (1992) “A história da cultura brasileira segundo as línguas nativas”. En da Cunha, M.C. (ed.), História dos índios no Brasil, São Paulo, Cia das Letras, pp. 87-102

Wieser, F. R. (1908) "Die karten von Amerika in dem Islario General des Alonso de Santa Cruz cosmógrafo mayor des Kaisers Karl V". Fur den XVI, Internat. Amerikanisten-Kongress, Innsbruck, pp. 55-57.

Wiessner, P. (1983) "Style and Social Information in Kalahari San Projectile Points". American Antiquity 48(2), pp. 253-276.

Zapata Gollan, A. (1945) "Los chaná en el territorio de la provincia de Santa Fe". Publicaciones del Departamento de Estudios Etnográficos y Coloniales 4, pp. 1-38.

Zárate, M, González, M., Flegenheimer, N. \& Bayón, C. (2002) "Sitios arqueológicos someros: El concepto de sitio en estratigrafía y sitio de superficie". Cuadernos del INAPL 19, pp. 635-653.

Zeballos, E. \& Pico, P. (1878) "Informe sobre el túmulo prehistórico de Campana". Anales de la Sociedad Científica Argentina 6, pp. 244-260.

\section{Notas}

\footnotetext{
${ }^{1}$ El nombre completo de quien dio a conocer el primer hallazgo arqueológico en el Delta del Paraná era Francisco Xavier Thomas de la Concepción Muñiz (1795-1871). Era médico de policía, Cirujano Mayor del Ejército en Cepeda y de la Guerra del Paraguay, interesado en la filosofía, el latín, la física y la matemática, senador, autoridad universitaria y profesor en la Escuela de Medicina de Buenos Aires (Podgorny 2010).
} 